\title{
Carbon Monoxide Releasing Molecule-2-Upregulated ROS-Dependent Heme Oxygenase-1 Axis Suppresses Lipopolysaccharide-Induced Airway Inflammation
}

\author{
Chih-Chung Lin ${ }^{1}$, Li-Der Hsiao ${ }^{1}$, Rou-Ling Cho ${ }^{2}$ and Chuen-Mao Yang ${ }^{1,2,3, *}$ \\ 1 Department of Anesthetics, Chang Gung Memorial Hospital at Linkuo, and College of Medicine, \\ Chang Gung University, Kwei-San, Tao-Yuan 33302, Taiwan \\ 2 Department of Physiology and Pharmacology and Health Aging Research Center, College of Medicine, \\ Chang Gung University, 259 Wen-Hwa 1 Road, Kwei-San, Tao-Yuan 33302, Taiwan \\ 3 Research Center for Chinese Herbal Medicine and Research Center for Food and Cosmetic Safety, \\ College of Human Ecology, Chang Gung University of Science and Technology, Tao-Yuan 33302, Taiwan \\ * Correspondence: chuenmao@mail.cgu.edu.tw or chuenmao@gmail.com; Tel.: +886-3-211-8800 (ext. 5123); \\ Fax:+886-3-211-8365
}

Received: 3 June 2019; Accepted: 26 June 2019; Published: 28 June 2019 updates

\begin{abstract}
The up-regulation of heme oxygenase-1 (HO-1) is mediated through nicotinamaide adenine dinucleotide phosphate (NADPH) oxidases (Nox) and reactive oxygen species (ROS) generation, which could provide cytoprotection against inflammation. However, the molecular mechanisms of carbon monoxide-releasing molecule (CORM)-2-induced HO-1 expression in human tracheal smooth muscle cells (HTSMCs) remain unknown. Here, we found that pretreatment with CORM-2 attenuated the lipopolysaccharide (LPS)-induced intercellular adhesion molecule (ICAM-1) expression and leukocyte count through the up-regulation of HO-1 in mice, which was revealed by immunohistochemistrical staining, Western blot, real-time PCR, and cell count. The inhibitory effects of HO-1 by CORM-2 were reversed by transfection with HO-1 siRNA. Next, Western blot, real-time PCR, and promoter activity assay were performed to examine the HO-1 induction in HTSMCs. We found that CORM-2 induced HO-1 expression via the activation of protein kinase $\mathrm{C}(\mathrm{PKC}) \alpha$ and proline-rich tyrosine kinase (Pyk2), which was mediated through Nox-derived ROS generation using pharmacological inhibitors or small interfering ribonucleic acids (siRNAs). CORM-2-induced HO-1 expression was mediated through Nox- $(1,2,4)$ or $\mathrm{p} 47^{\text {phox }}$, which was confirmed by transfection with their own siRNAs. The Nox-derived ROS signals promoted the activities of extracellular signal-regulated kinase 1/2 (ERK1/2). Subsequently, c-Fos and c-Jun-activator protein-1 (AP-1) subunits-were up-regulated by activated ERK1/2, which turned on transcription of the HO-1 gene by regulating the HO-1 promoter. These results suggested that in HTSMCs, CORM-2 activates PKC $\alpha / P y k 2$-dependent Nox/ROS/ERK1/2/AP-1, leading to HO-1 up-regulation, which suppresses the lipopolysaccharide (LPS)-induced airway inflammation.
\end{abstract}

Keywords: CORM-2; NADPH oxidase; ROS; AP-1; HO-1

\section{Introduction}

Heme oxygenase $(\mathrm{HO})$, a rate-limiting enzyme, metabolizes heme to biliverdin-IX $\alpha$, ferrous iron, and carbon monoxide (CO). These secondary products are involved in the regulation of different physiological processes. HO-1, a member of the HO family [1,2], is inducible and directly protects various organs from oxidative damages [1,3]. Biliverdin-IX $\alpha$ is converted to the endogenous radical scavenger bilirubin-IX $\alpha$ and has anti-inflammatory properties [4,5]. The ferrous iron is rapidly sequestered with ferritin to function additional antioxidant and anti-apoptotic effects $[5,6]$. Moreover, 
$\mathrm{CO}$ has been shown to exert anti-apoptotic and anti-inflammatory effects that are mediated via HO-1 up-regulation $[4,7,8]$. However, several pro-inflammatory cytokines and oxidative stresses can also trigger HO-1 expression [9-11]. For example, $\mathrm{HO}-1$ is also induced by various factors in the airway cells of asthmatic patients [12]. Accumulating evidence concerning HO-1/CO-dependent cytoprotection elicits the mechanisms involved in the modulation of the inflammatory responses, including the down-regulation of pro-inflammatory mediators, atherosclerosis, ischemia-reperfusion systems, and airway disorders $[8,13,14]$

Nicotinamaide adenine dinucleotide phosphate (NADPH) oxidase (Nox)-derived reactive oxygen species (ROS) generation has been approved to regulate either the expression of inflammatory or anti-inflammatory mediators in the airway and pulmonary diseases [15]. Excessive ROS production can regulate the expression of various inflammatory genes during airway disorders $[15,16]$. In contrast, low levels of ROS contribute to maintain cellular redox homeostasis under physiological conditions [15]. Several studies indicate that the exogenous application of $\mathrm{CO}$ and $\mathrm{HO}-1$ can protect against oxidative stress and hyperoxic injury in the various organs $[17,18]$. It has also been reported that the up-regulation of HO-1 via the Nox/ROS formation is induced by lipopolysaccharide (LPS) or cytokines $[8,19]$. In addition, our previous reports have indicated that the Nox/ROS system is a key player for HO-1 expression induced by lipotechoic acid (LTA) and cigarette smoke particle extract (CSPE) in human tracheal smooth muscle cells (HTSMCs) $[5,20]$. Our previous studies and others have demonstrated that the carbon monoxide-releasing molecule (CORM)-2 mediates the Nox-dependent ROS generation in astrocytes [21,22] and human bronchial smooth muscle cells [23]. CORMs have been confirmed to provide the exogenous $\mathrm{CO}$ source and induce HO-1 expression in several cell types $[8,9,24]$. However, the roles of Nox/ROS involved in CORM-2-induced HO-1 expression were still unknown. HO-1 expression is regulated by various intracellular signaling pathways, such as ROS, growth factor receptors, non-receptor tyrosine kinases such as Pyk2, or mitogen-activated protein kinases (MAPKs) $[25,26]$. In our previous study, CORM-2 has been shown to induce HO-1 expression via c-Src/epidermal growth factor receptor (EGFR)/phosphoinositide 3-kinase (PI3K)/Akt/c-Jun N-terminal kinase 1/2 (JNK1/2) and p38 MAPK pathways in HTSMCs [27]. We also noticed that many stress-activated response elements on the upstream region of the HO-1 promoter, such as nuclear factor erythroid 2-related factor 2 (Nrf2) and activator protein 1 (AP-1), are involved in the expression of HO-1 in response to oxidative stresses [28,29]. Therefore, whether an alternative Nox/ROS-mediated pathway involved in HO-1 expression induced by CORM- 2 has yet to be investigated in HTSMCs.

Besides, several reports have shown that administration with low concentrations of $\mathrm{CO}$ or pharmacological application of CORMs can also confer protective effects in the models of inflammatory responses and tissue injury [26,30,31]. Accumulating evidence has indicated that CORM-2-liberated $\mathrm{CO}$ reduces inflammatory responses in sepsis by interfering with nuclear factor (NF)- $\mathrm{KB}$ activation [32]. Moreover, the overexpression of HO- 1 by cobalt protoporphyrin (CoPPIX) can reduce tumor necrosis factor (TNF) $\alpha$-induced oxidative stress and airway inflammation [7]. Therefore, CORM-2-induced HO-1 gene expression could prevent inflammatory responses. However, the detailed mechanisms by which CORM-2 induced HO-1 expression in HTSMCs are still unclear. Our results demonstrated that CORM-2-induced HO-1 expression is mediated via protein kinase $\mathrm{C}(\mathrm{PKC}) \alpha /$ proline-rich tyrosine kinase 2 (Pyk2)-dependent Nox/ROS generation linking to the ERK1/2-mediated activation of AP-1 in HTSMCs, which could protect against the lipopolysaccharide (LPS)-induced airway inflammatory diseases.

\section{Results}

\subsection{CORM-2 Inhibits LPS-Induced Lung Inflammation in Mice}

CORM-2 has been shown to protect against inflammatory responses induced by various insults $[4,7,8]$. First, we investigated the anti-inflammatory effects of CORM-2 on LPS-induced lung inflammation. We observed that LPS markedly induced intercellular adhesion molecule-1 
(ICAM-1) expression, which was attenuated by CORM-2 via HO-1 expression, as determined by immunohistochemistry staining (Figure 1A). Bronchoalveolar lavage (BAL) fluid was collected to determine the number of leukocytes, and airway tissues were harvested to study the levels of protein and mRNA expression. As shown in Figure 1B,D, LPS significantly enhanced ICAM-1 protein expression and leukocytes count in BAL fluid. LPS also significantly induced ICAM-1 messenger ribonucleic acid (mRNA) expression (Figure 1C). In addition, pretreatment with CORM-2 also inhibited the LPS-induced ICAM-1 protein expression in HTSMCs (Figure 1E). Further, we confirmed the inhibitory effects of HO- 1 induction by CORM-2 on the LPS-up-regulated ICAM-1 expression by transfection with HO-1 siRNA. We found that CORM-2 attenuated the LPS-induced ICAM-1 expression, which was partially reversed by transfection with HO-1 siRNA (Figure 1F). All of these LPS-mediated responses were attenuated by CORM-2 via the up-regulation of $\mathrm{HO}-1$ in the airway tissues of mice (Figure 1). These results suggested that the up-regulation of HO-1 by CORM-2 protects airway tissues against the LPS-mediated inflammatory responses.

A
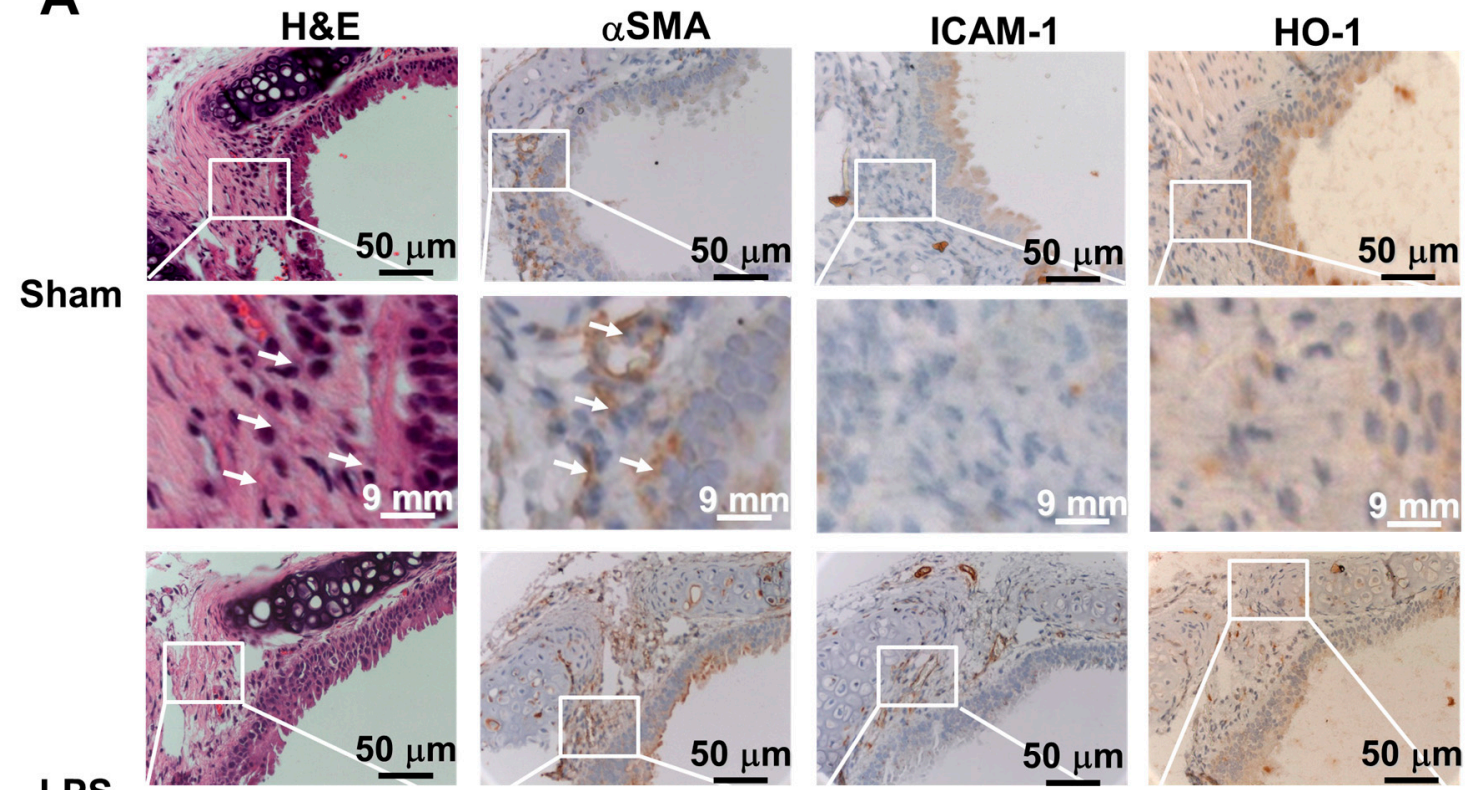

LPS
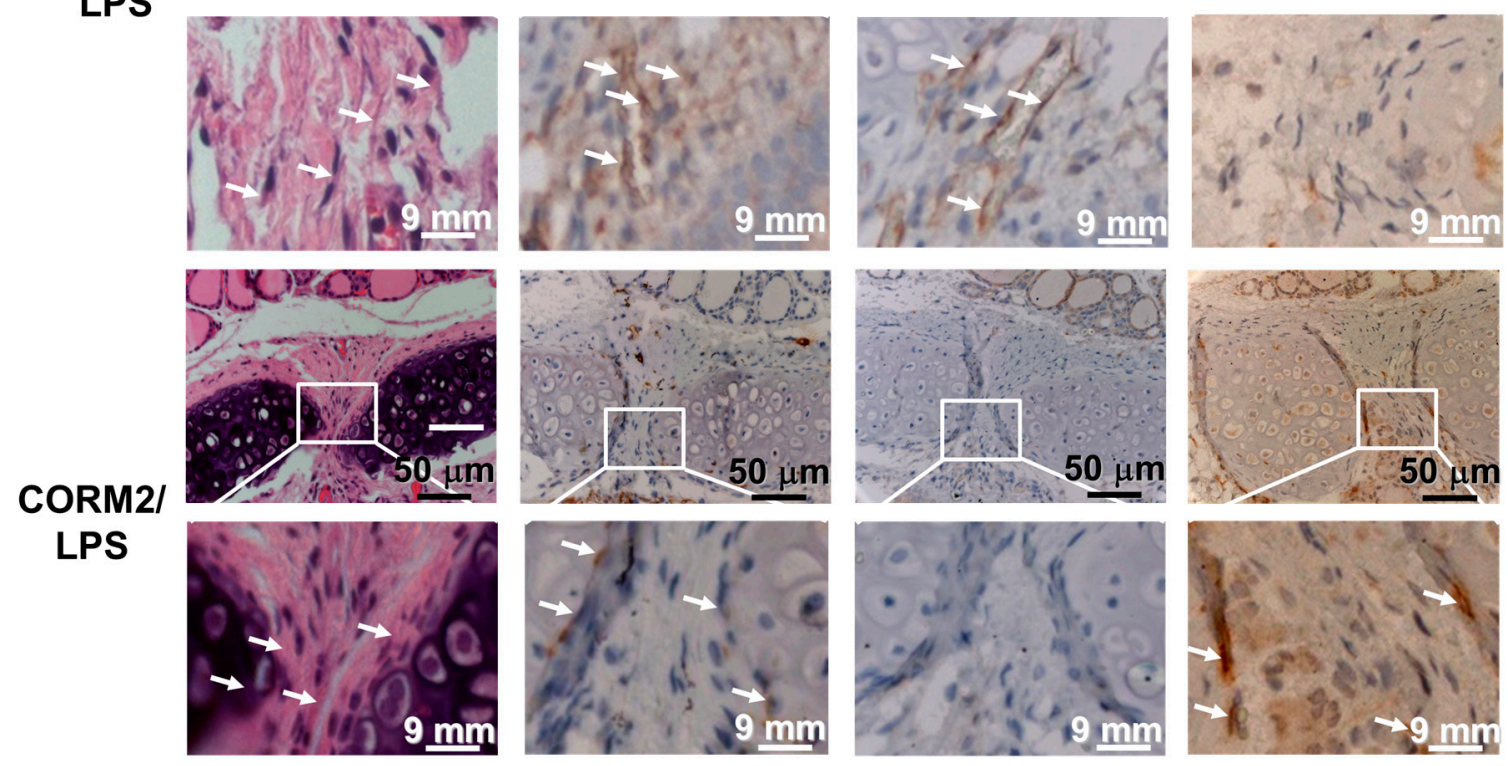

Figure 1. Cont. 

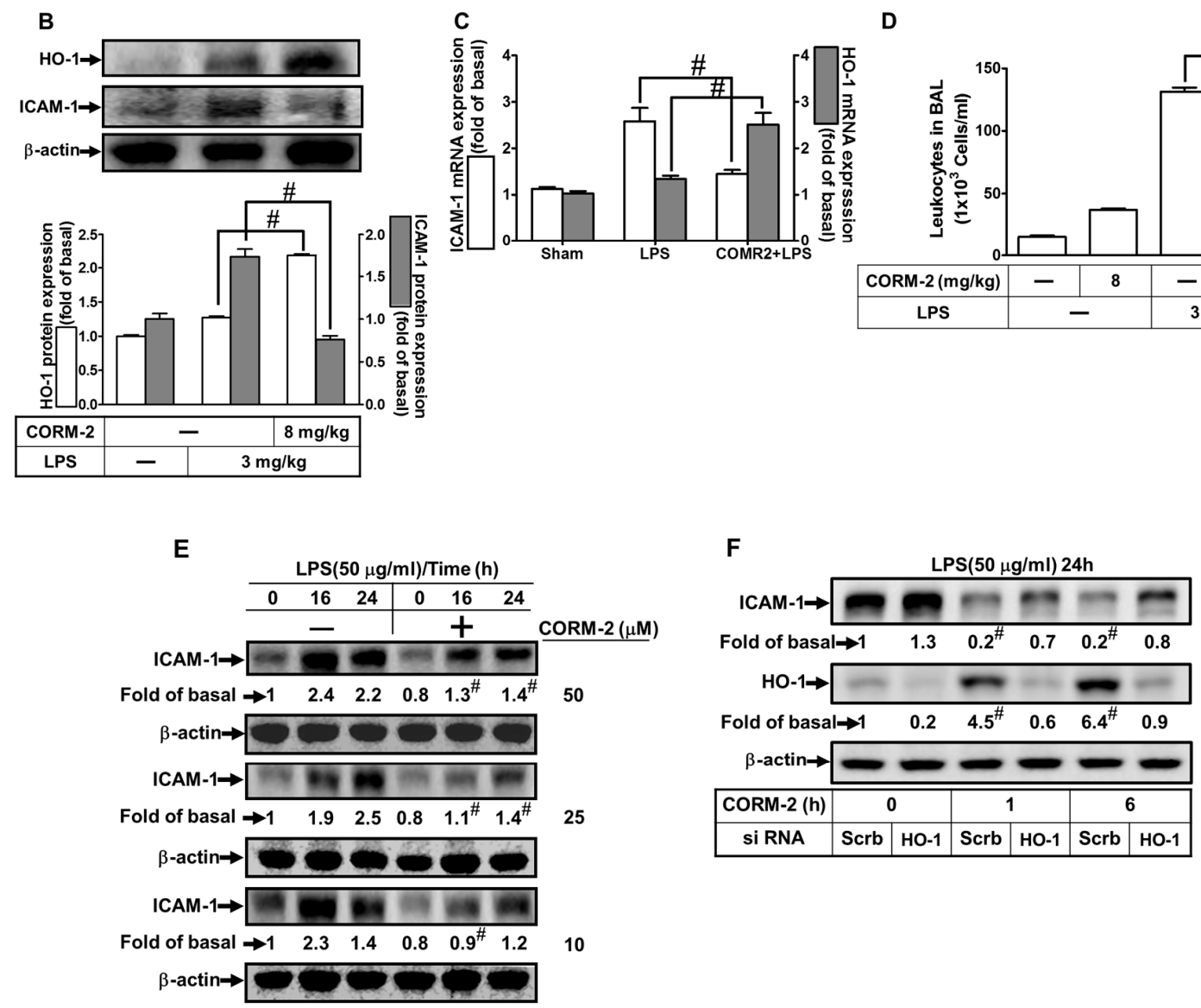

Figure 1. Induction of heme oxygenase (HO-1) by carbon monoxide-releasing molecule (CORM-2) suppresses intercellular adhesion molecule-1 (ICAM-1) expression and leukocyte infiltration in HTSMCs and mice. Institute of Cancer Research (ICR) mice were pretreated with CORM-2 (8 mg/kg of body weight) for $24 \mathrm{~h}$, and then treated with lipopolysaccharide (LPS) ( $3 \mathrm{mg} / \mathrm{kg}$ of body weight). (A) $\mathrm{H}$ (hematoxylin) \& E (Eosin) and immunohistochemical staining for $\alpha$-smooth muscle actin $(\alpha$-SMA), ICAM-1, and HO-1 in serial section of the airway tissues from sham [0.1 mL of DMSO-PBS (phosphate-buffered saline) (1:100) with $0.1 \%(w / v)$ BSA (bovine serum albumin) treated mice], LPS (LPS-injected mice) and CORM-2 + LPS mice. The arrows indicate tracheal smooth muscle cells displayed with ICAM-1 and HO-1 expression. (B,C) Airway tissues were homogenized to extract proteins and mRNAs (messenger ribonucleic acids), and analyzed by (B) Western blot and (C) real-time PCR to determine the levels of HO-1, ICAM-1, and $\beta$-actin (served as an internal control) protein and mRNA expression, respectively. (D) BAL fluid was collected to count the number of leukocytes infiltration. (E) Human tracheal smooth muscle cells (HTSMCs) were pretreated without or with various concentrations of CORM-2 for $1 \mathrm{~h}$ and then incubated with LPS $(50 \mu \mathrm{g} / \mathrm{mL})$ for the indicated time periods. The levels of ICAM- 1 and $\beta$-actin were determined by Western blot. (F) Cells were transfected with scrambled (Scrb) or HO-1 siRNA (small interfering ribonucleic acid), incubated with CORM-2 $(50 \mu \mathrm{M})$ for 1 or $6 \mathrm{~h}$, and then stimulated with LPS $(50 \mu \mathrm{g} / \mathrm{mL})$ for $16 \mathrm{~h}$. The levels of ICAM-1, HO- 1 , and $\beta$-actin protein were determined by western blot. Data are expressed as mean \pm SEM of five independent experiments $(n=5)$. ${ }^{\#} p<0.05$, as compared with the mice exposed to the indicated reagents. Data analysis and processing are described in the section "Statistical Analysis of Data".

\subsection{ROS Participate in CORM-2-Induced HO-1 Expression}

Low levels of ROS have been shown to contribute to maintain cellular redox homeostasis and protect cells against oxidative stress through the up-regulation of HO-1 [8,19]. To examine whether ROS participate in HO-1 induction in HTSMCs, a ROS scavenger N-acetyl cysteine (NAC) was used for this purpose. We found that pretreatment with NAC concentration-dependently attenuated the 
CORM-2-induced both of HO-1 protein (Figure 2A) and mRNA expression (Figure 2B), suggesting the involvement of ROS in the CORM-2-induced HO-1 expression. Next, we evaluated whether CORM-2 stimulated ROS generation and the scavenging efficacy of NAC. Our results indicated that CORM-2 stimulated ROS generation in a time-dependent manner with a maximal response within $4 \mathrm{~h}$ (Figure 2C), which was markedly attenuated by pretreatment with $10 \mathrm{mM}$ of NAC (Figure 2D), indicating that NAC can efficiently scavenge ROS in HTSMCs. These results were further supported by the data of $2^{\prime}, 7^{\prime}$-chloromethyl 2', $7^{\prime}$-dichloro fluorescein diacetate (CMH2DCF-DA; for $\mathrm{H}_{2} \mathrm{O}_{2}$ ) and dihydroethidium (DHE; for $\mathrm{O}_{2}^{-}$) fluorescence images observed under a fluorescent microscope (Figure 2E). Pretreatment of HTSMCs with NAC (10 mM) significantly reduced CORM-2-stimulated $\mathrm{H}_{2} \mathrm{O}_{2}$ and $\mathrm{O}_{2}{ }^{-}$generation. In addition, treatment with an inactive form of CORM-2 [iCORM-2, ruthenium (III) chloride, $\mathrm{RuCl}_{3}$ ] [33] failed to induce HO-1 expression (Figure 2F). These results concluded that ROS generation stimulated by CORM-2 contributes to up-regulation of HO-1 in HTSMCs.

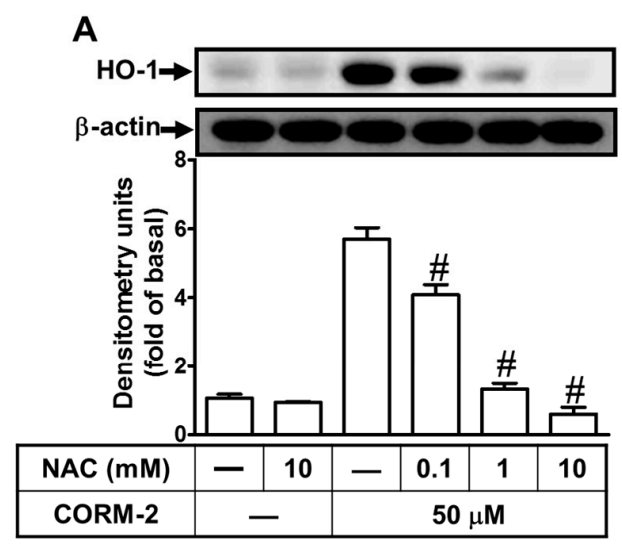

C

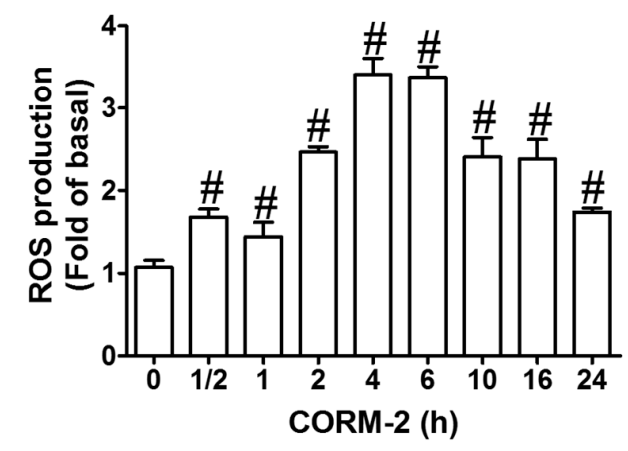

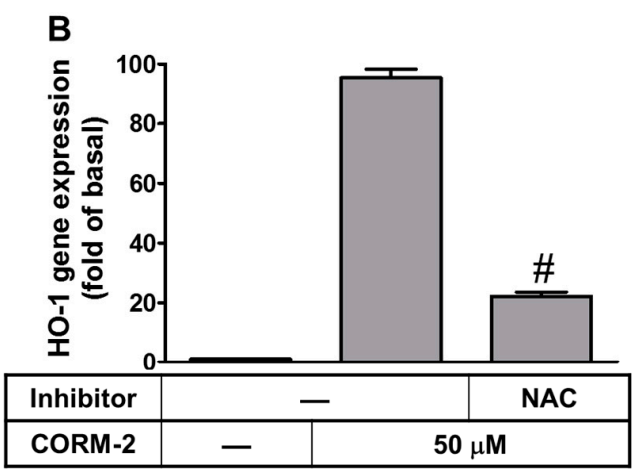

D

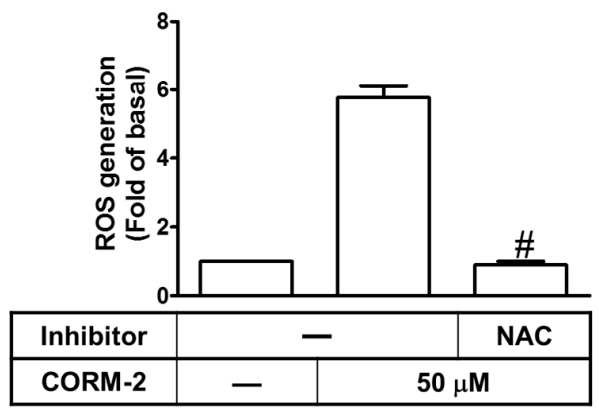

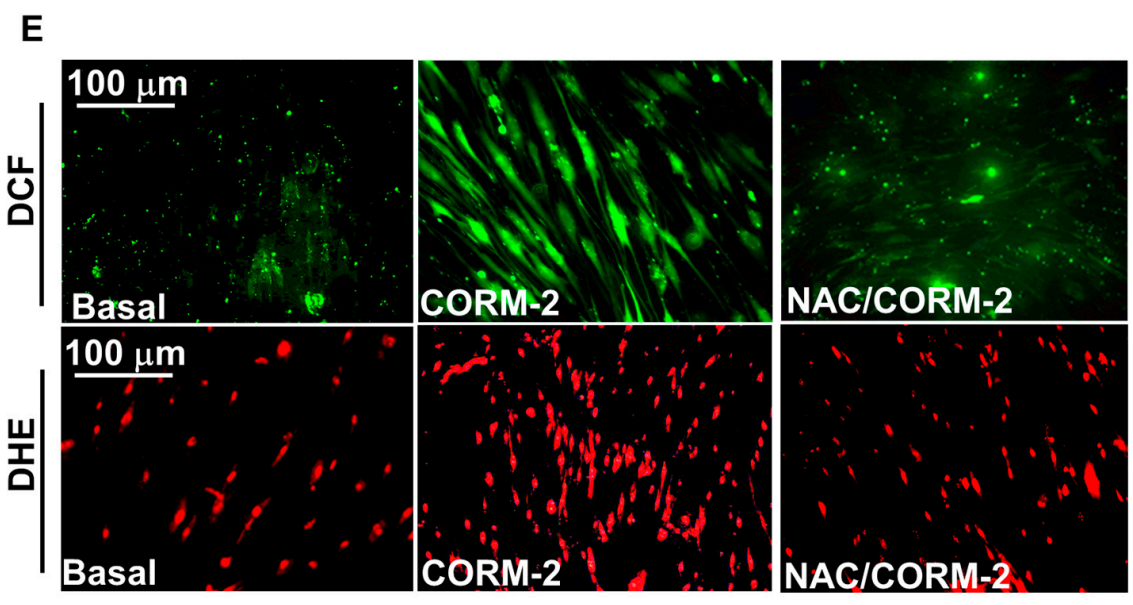

Figure 2. Cont. 


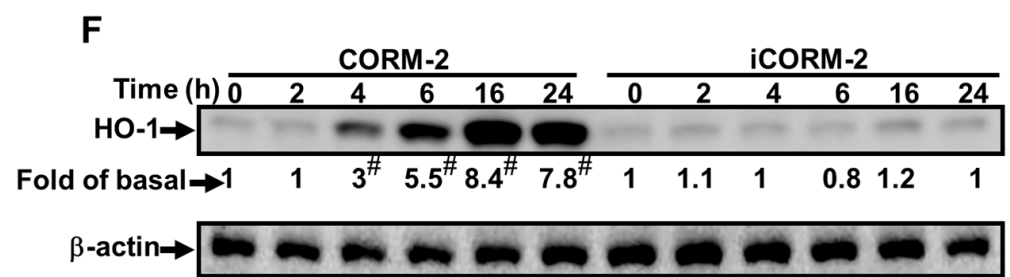

Figure 2. Reactive oxygen species (ROS) are required for CORM-2-induced HO-1 expression in HTSMCs. (A) Cells were pretreated with $\mathrm{N}$-acetyl cysteine (NAC) for $1 \mathrm{~h}$ and then incubated with CORM-2 for $24 \mathrm{~h}$. The protein levels of HO- 1 and $\beta$-actin (served as an internal control) were determined by Western blot. (B) Cells were pretreated with NAC $(10 \mathrm{mM})$ for $1 \mathrm{~h}$, and then incubated with CORM-2 for $6 \mathrm{~h}$. The mRNA expression of HO-1 was determined by real-time PCR. (C) Cells were incubated with the 2',7'-dichlorofluorescin diacetate (DCF-DA) $(5 \mu \mathrm{M})$ for $45 \mathrm{~min}$, followed by stimulation with $50 \mu \mathrm{M}$ of CORM-2 for the indicated time intervals. (D) Cells were pretreated without or with NAC $(10 \mathrm{mM})$ for $1 \mathrm{~h}$ before exposure to CORM-2 for $6 \mathrm{~h}$. (C,D) The fluorescence intensity of cells was determined. (E) DCF-DA, and dihydroethidium (DHE) staining, cells were treated with CORM-2 for $6 \mathrm{~h}$ in the absence or presence of NAC $(10 \mathrm{mM})$. The fluorescence images were observed by a fluorescence microscope. Image of fluorescence microscope, 400×. (F) Cells were treated with $50 \mu \mathrm{M}$ of CORM-2 or iCORM-2 for the indicated time intervals. The protein levels of HO-1 were determined by Western blot. Data are expressed as mean \pm SEM of five independent experiments $(n=5)$. ${ }^{\#} p<0.05$, as compared with the cells exposed to vehicle $(\mathbf{C}, \mathbf{F})$ or CORM-2 (A,B,D) alone. Data analysis and processing are described in the section "Statistical Analysis of Data".

\subsection{Nox-Derived ROS Generation Contributes to CORM-2-Induced HO-1 Expression}

CORM-2 mediates the Nox-dependent ROS generation, leading to HO-1 expression $[8,9,24]$. Thus, the roles of Noxs in the ROS-dependent HO-1 expression were investigated. The inhibitors of Nox (diphenyleneiodonium, DPI) and p47 ${ }^{\text {phox }}$ (apocynin, APO) were used to investigate whether Noxs mediated ROS-dependent HO-1 expression in CORM-2-treated HTSMCs. As shown in Figure 3A,B, pretreatment with either DPI or APO significantly attenuated CORM-2-induced both HO-1 protein and mRNA expression. To further investigate whether CORM-2 stimulates Nox activity, as shown in Figure 3C, CORM-2 time-dependently stimulated Nox activity, significantly increased within $30 \mathrm{~min}$ and sustained up to $24 \mathrm{~h}$, which was blocked by pretreatment with either DPI $(10 \mu \mathrm{M})$ or APO $(100 \mu \mathrm{M})$ (Figure 3D, grey bars), accompanied with inhibiting the ROS generation induced by CORM-2 (Figure 3D, open bars). These results were further supported by the data of DCF (dichlorofluorescein) (for $\mathrm{H}_{2} \mathrm{O}_{2}$ ) and DHE (for $\mathrm{O}_{2}^{-}$) fluorescence images observed under a fluorescent microscope (Figure $3 \mathrm{~F}$ ), suggesting that CORM-2-stimulated Nox-derived ROS generation contributes to HO-1 expression. Moreover, we found that Nox/ROS generation stimulated by CORM- 2 was mediated via Nox $(1,2,4)$ or p47 $7^{\text {phox }}$, which was confirmed by using their own siRNAs in HTSMCs (Figure 3G).
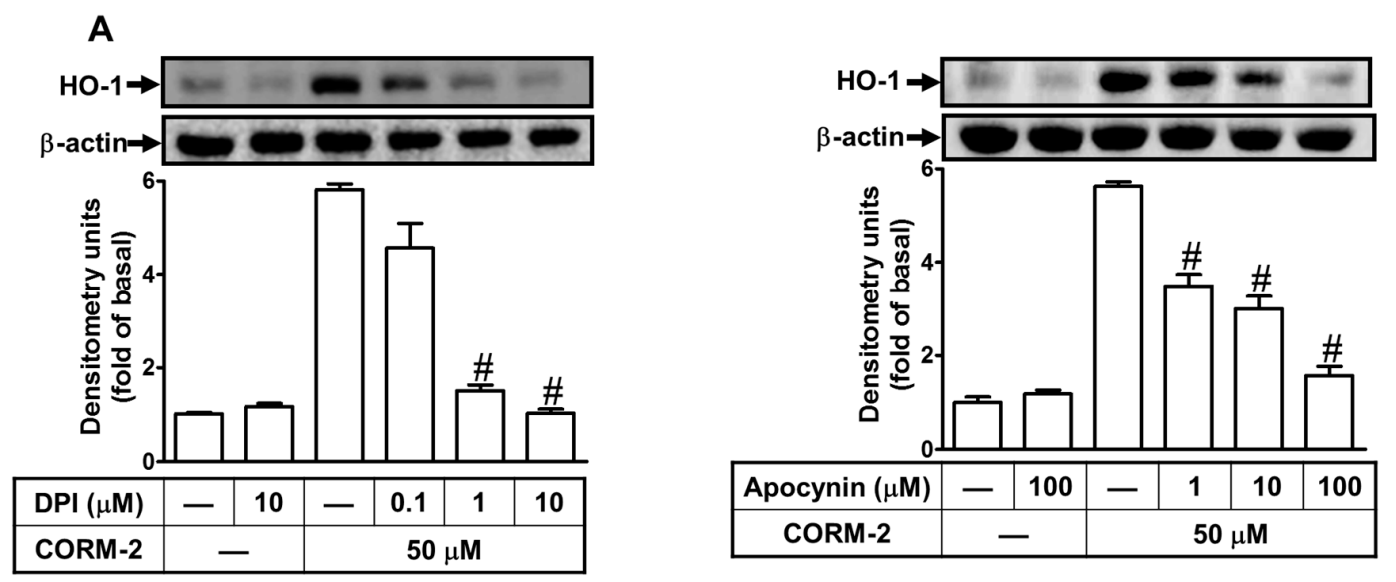

Figure 3. Cont. 
B

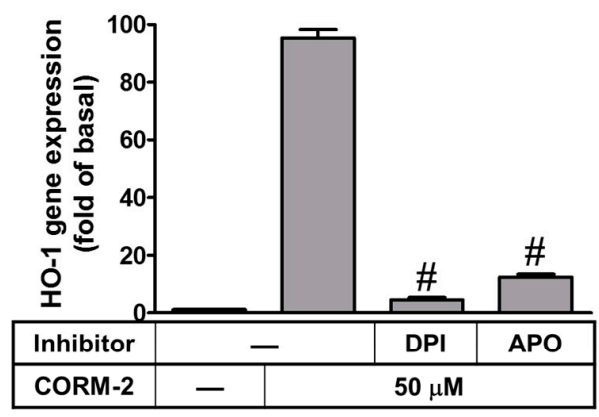

D

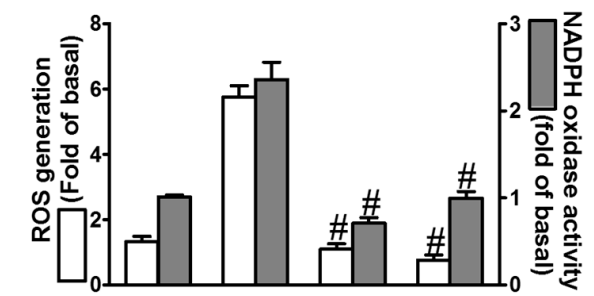

\begin{tabular}{|c|c|c|c|}
\hline Inhibitor & - & DPI & APO \\
\hline CORM-2 & - & $50 \mu \mathrm{M}$ & \\
\hline
\end{tabular}

F

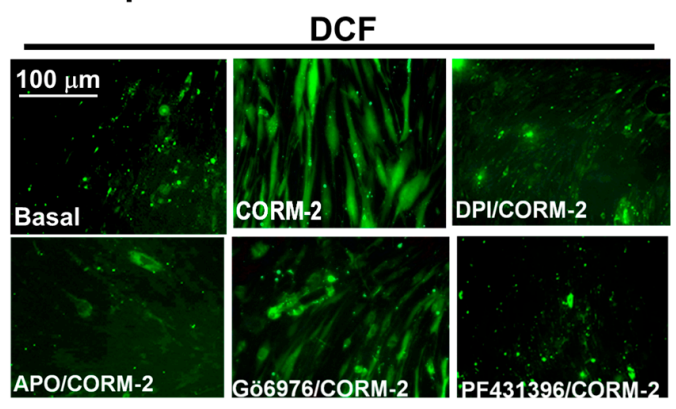

G
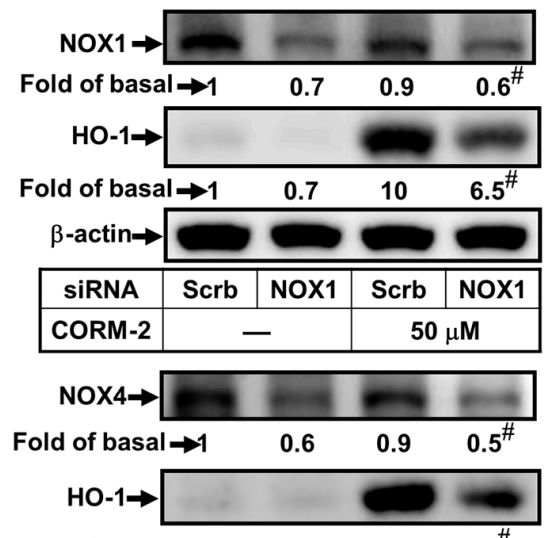

Fold of basal $\rightarrow 1 \quad 0.7 \quad 9.7 \quad 6.8^{\#}$

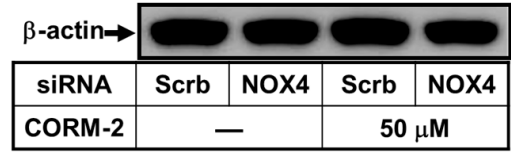

C

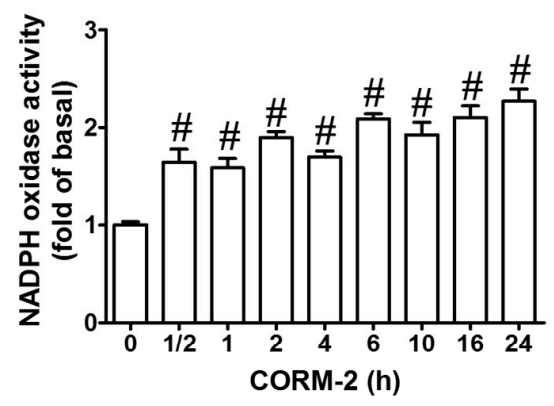

E

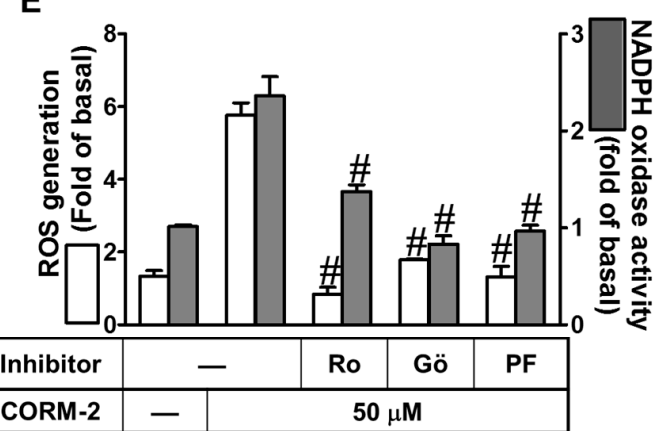

DHE
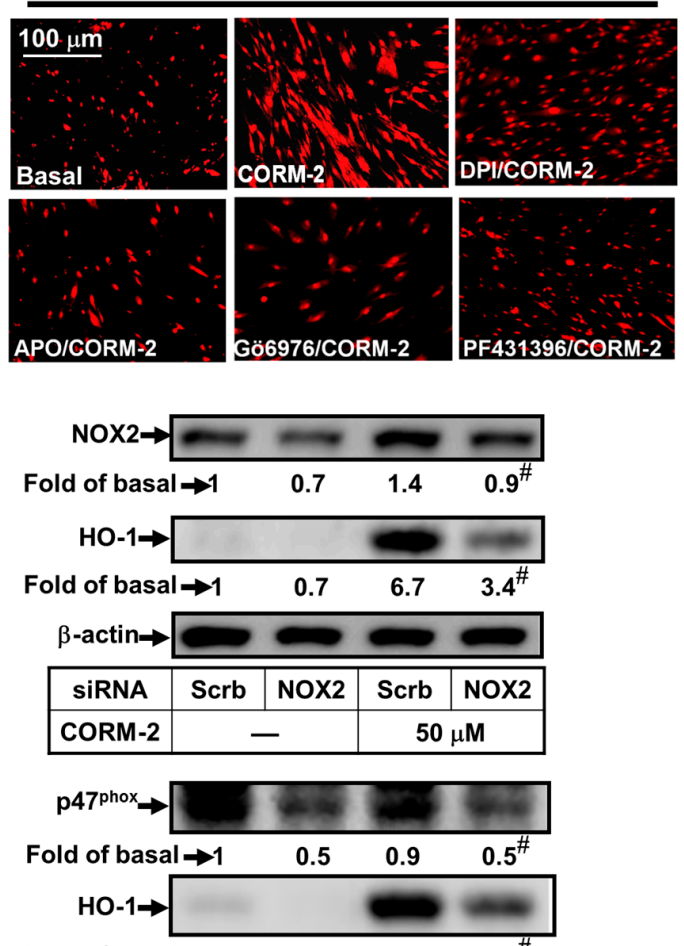

Fold of basal $\rightarrow 1 \quad 0.8 \quad 9.5 \quad 4.2^{\#}$

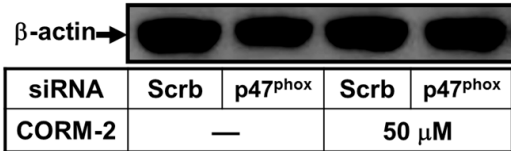

Figure 3. Nicotinamaide adenine dinucleotide phosphate (NADPH) oxidase-dependent ROS generation contributes to CORM-2-induced HO-1 expression in HTSMCs. (A) Cells were pretreated without or with diphenyleneiodonium (DPI) or apocynin (APO) for $1 \mathrm{~h}$ before exposure to CORM-2 for $24 \mathrm{~h}$. 
The protein levels of HO- 1 and $\beta$-actin (served as an internal control) were determined by Western blot. (B) Cells were pretreated with DPI $(10 \mu \mathrm{M})$ or APO $(100 \mu \mathrm{M})$ for $1 \mathrm{~h}$, and then incubated with CORM-2 for $6 \mathrm{~h}$. The mRNA expression of HO-1 was determined by real-time PCR. (C) Cells were incubated with CORM-2 $(50 \mu \mathrm{M})$ for the indicated time intervals. The Nox activity was analyzed. (D,E) Cells were pretreated without or with (D) DPI $(10 \mu \mathrm{M})$ or APO $(100 \mu \mathrm{M})$, and (E) Ro31-8220 $(10 \mu \mathrm{M})$, Gö6976 $(10 \mu \mathrm{M})$, or PF431396 $(10 \mu \mathrm{M})$ for $1 \mathrm{~h}$, and then incubated with CORM-2 for $6 \mathrm{~h}$. The Nox activity and ROS generation were analyzed. (F) CMH2, DCF-DA, and DHE staining, cells were treated with CORM-2 for $6 \mathrm{~h}$ in the absence or presence of DPI $(10 \mu \mathrm{M})$, APO $(100 \mu \mathrm{M})$, Gö6976 (10 $\mu \mathrm{M})$, or PF431396 $(10 \mu \mathrm{M})$. The fluorescence images were detected by a fluorescence microscope. Image of fluorescence microscope, 400×. (G) Cells were transfected with either scrambled (Scrb), Nox-(1,2,4), or p47phox siRNA, and then incubated with CORM-2 for $24 \mathrm{~h}$. The levels of Nox-(1,2,4), p47 ${ }^{\text {phox }}, \mathrm{HO}-1$, and $\beta$-actin (served as an internal control) protein were determined by Western blot. Data are expressed as mean \pm SEM of five independent experiments $(n=5) .{ }^{\#} p<0.05$, as compared with the cells exposed to vehicle $(\mathbf{C}, \mathbf{G})$ or CORM-2 alone (A,B,D,E). Data analysis and processing are described in the section "Statistical Analysis of Data".

\subsection{CORM-2 Induces HO-1 Expression via PKC $\alpha$}

Our previous report and the others also indicate that PKCs are involved in $\mathrm{HO}-1$ expression in brain astrocytes [25]. Thus, we investigated whether PKC members are involved in the CORM-2-induced HO-1 expression. We found that pretreatment of HTSMCs with Ro31-8220 (a pan-PKC inhibitor) concentration-dependently attenuated the HO-1 induction by CORM-2 (Figure 4A). Next, to determine which PKC isoforms, PKC $\alpha$ especially, mediate CORM-2-induced HO-1 expression, two selective PKC $\alpha$ inhibitors (Gö6976 and Gö6983) were used for these purposes. The usage of Gö6983, an ATP-competitive bisindolylmaleimide PKC inhibitor, blocks the PKC phosphorylation [34]. Our previous report also indicates that Go66983 inhibits PKC $\alpha / \beta I I$ phosphorylation stimulated by thrombin in SK-N-SH (human neuroblastoma) cells [35]. We found that pretreatment with either Gö6976 or Gö6983 concentration-dependently blocked CORM-2-induced HO-1 expression in HTSMCs (Figure 4A), indicating that PKC $\alpha$ was involved in CORM-2-induced HO-1 expression. Moreover, pretreatment

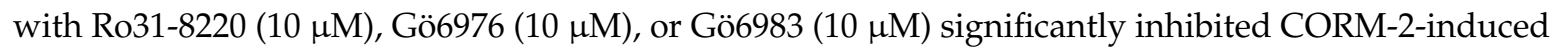
HO-1 mRNA expression (Figure 4B). The role of PKC $\alpha$ in CORM-2-induced HO-1 expression was further confirmed by transfection with PKC $\alpha$ siRNA, which significantly knocked down PKC $\alpha$ protein and blocked the CORM-2-induced HO-1 expression (Figure 4C). In addition, the activation of PKC $\alpha / \beta I I$ in CORM-2-induced responses was confirmed by determining their phosphorylation. As shown in Figure 4D, CORM-2 time-dependently stimulated PKC $\alpha / \beta I I$ phosphorylation with a maximal response within 2-4 h, which was attenuated by pretreatment with Gö6983 (10 $\mu \mathrm{M})$, but not by pretreatment with $\mathrm{APO}, \mathrm{DPI}$, or NAC, indicating that PKC $\alpha / \beta \mathrm{II}$ are the upstream components of Nox/ROS in HO-1 expression. This note was also supported by the results that pretreatment with either Ro31-8220 or Gö6976 inhibited the CORM-2-stimulated Nox activity and ROS generation (Figure 3E,F). These results suggested that $\mathrm{HO}-1$ expression induced by CORM-2 is mediated via PKC $\alpha / \beta I I-d e p e n d e n t$ Nox activation and ROS generation in HTSMCs.

\subsection{Involvement of Pyk2 in CORM-2-Induced HO-1 Expression}

Previous reports have indicated that PF431396 treatment attenuates proline-rich tyrosine kinase 2 (Pyk2) phosphorylation at Tyr (tyrosine) ${ }^{402}$ in various types of cells [36,37]. To investigate the role of Pyk2 in HO-1 expression, PF431396 (a Pyk2 inhibitor) was used. In this study, we found that pretreatment with PF431396 concentration-dependently attenuated CORM-2-induced both of HO-1 protein (Figure 5A) and mRNA (Figure 5B) expression. To confirm the role of Pyk2 in CORM-2-induced HO-1 expression, Pyk2 siRNA transfection significantly knocked down the Pyk2 protein level and inhibited CORM-2-induced HO-1 expression (Figure 5C). We further determined whether CORM-2 stimulated activation of Pyk2; the phosphorylation of Pyk2 was detected by Western blot. As shown in Figure 5D, CORM-2 time-dependently stimulated Pyk2 phosphorylation, which was attenuated by 
pretreatment of PF431396 $(10 \mu \mathrm{M})$, but not by APO, DPI, or NAC, indicating that Pyk2 is an upstream component of Nox/ROS in HO-1 expression. This note was also supported by the results that PF431396 attenuated the CORM-2-triggered Nox activity and ROS generation (Figure 3E,F). These findings indicated that HO-1 expression by CORM-2 is mediated via a Pyk2-dependent Nox/ROS activity in HTSMCs.
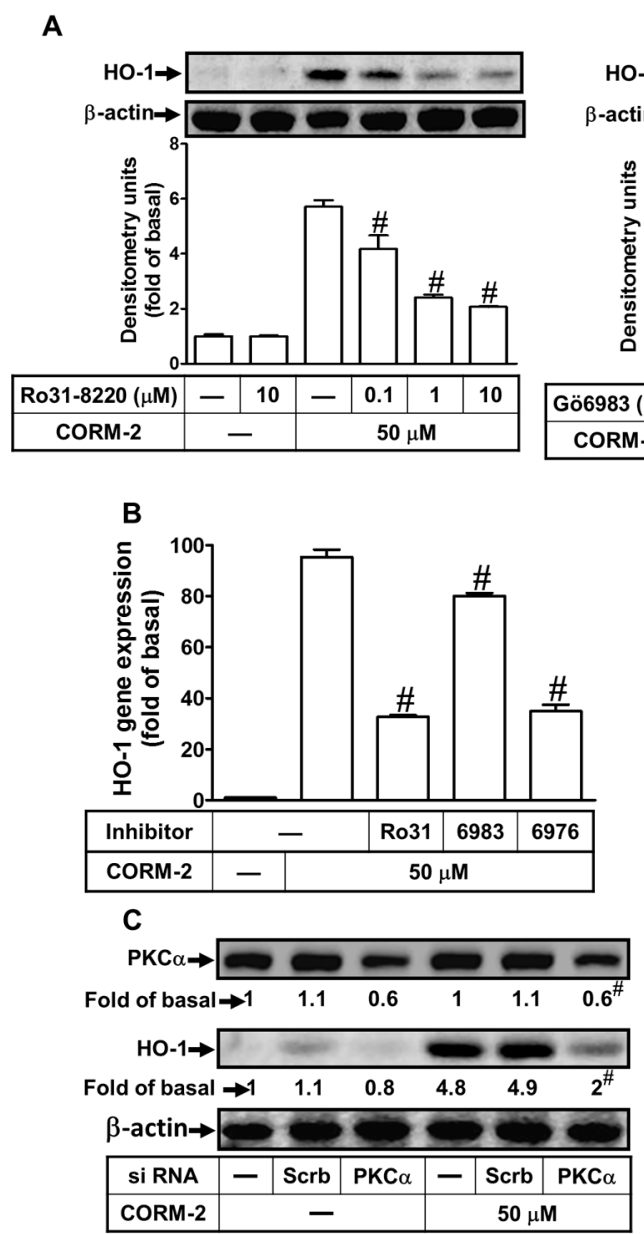
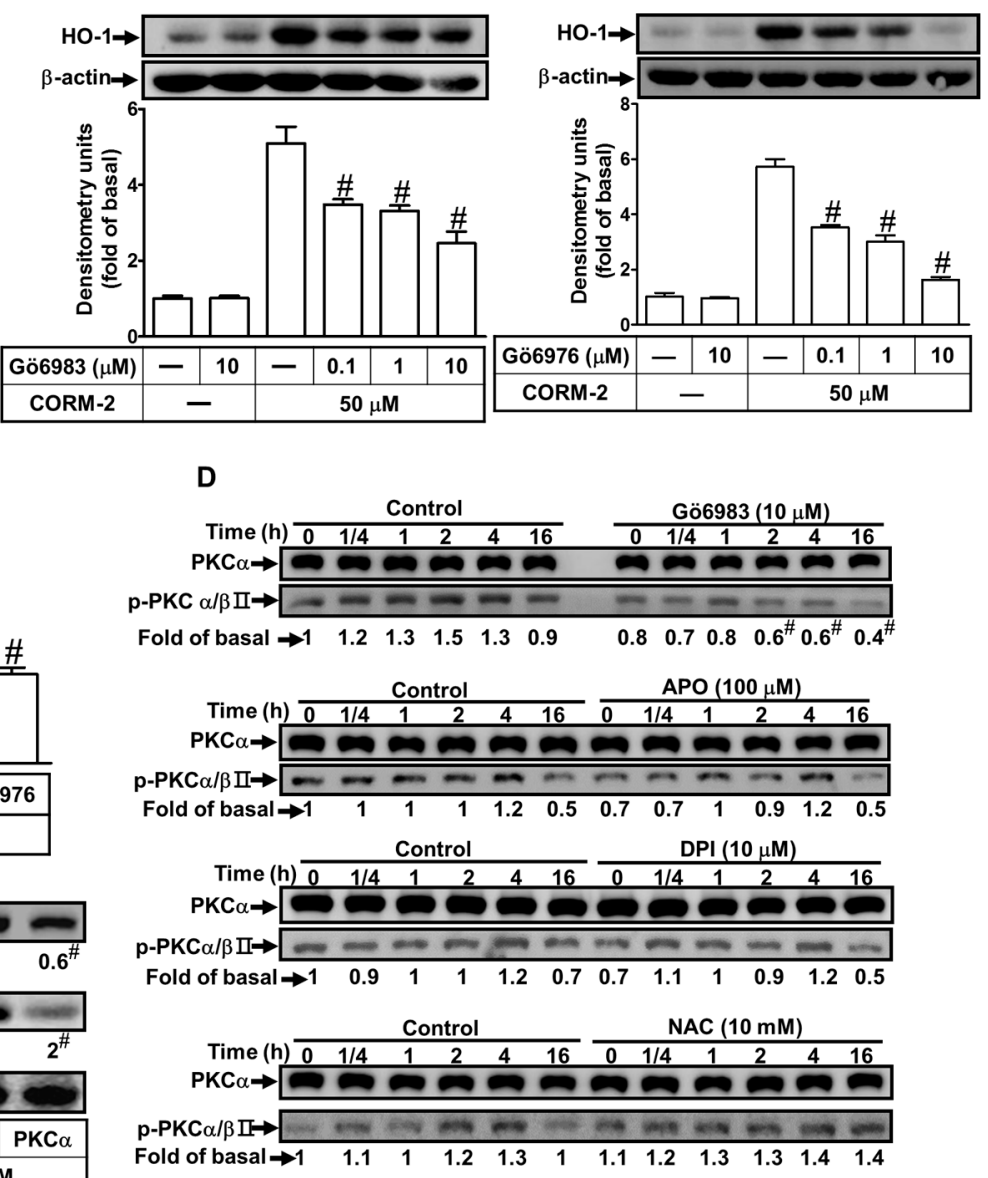

Figure 4. CORM-2 induces HO-1 expression via a PKC $\alpha$-dependent pathway in HTSMCs. (A) Cells were pretreated with Ro31-8220, Gö6983, or Gö6976 for 1 h, and then incubated with CORM-2 (50 $\mu$ M) for $24 \mathrm{~h}$. The protein levels of HO- 1 and $\beta$-actin (served as an internal control) were determined by

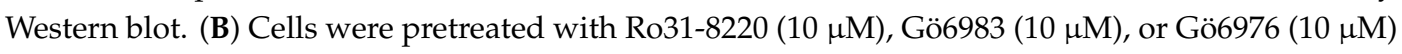
for $1 \mathrm{~h}$, and then incubated with CORM-2 for $6 \mathrm{~h}$. The mRNA expression of HO-1 was determined by real-time PCR. (C) Cells were transfected with either scrambled (Scrb) or protein kinase C (PKC $\alpha$ ) siRNA, and then incubated with CORM-2 for $24 \mathrm{~h}$. The levels of PKC $\alpha, \mathrm{HO}-1$, and $\beta$-actin (served as an internal control) protein were determined by Western blot. (D) Cells were pretreated without or with Gö6983 $(10 \mu \mathrm{M})$, APO $(100 \mu \mathrm{M})$, DPI $(10 \mu \mathrm{M})$, or NAC $(10 \mathrm{mM})$ for $1 \mathrm{~h}$, and then incubated with CORM-2 for the indicated time intervals. The levels of phospho-PKC $\alpha$ and PKC $\alpha$ were determined by Western blot. Data are expressed as mean \pm SEM of five independent experiments $(n=5)$. ${ }^{\#} p<0.05$, as compared with the cells exposed to CORM-2 alone. Data analysis and processing are described in the section "Statistical Analysis of Data". 
A

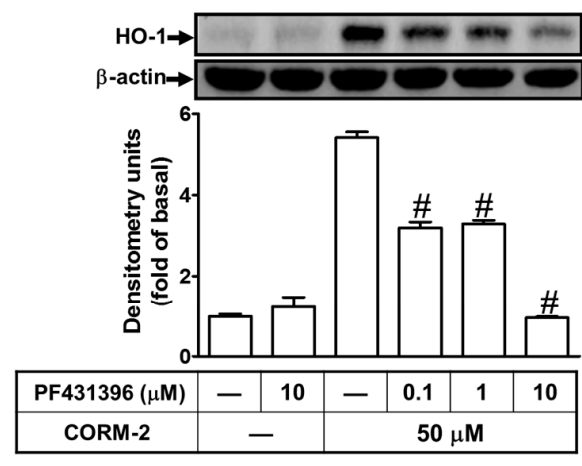

B

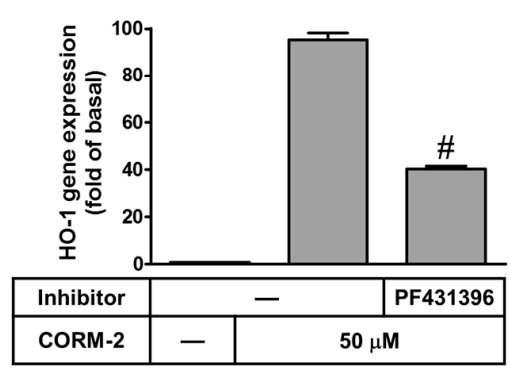

C

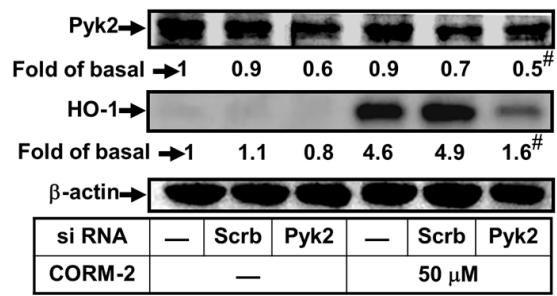

D

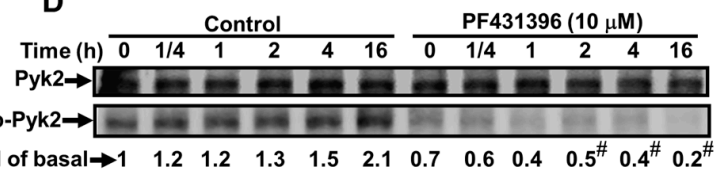

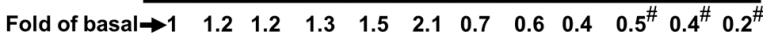

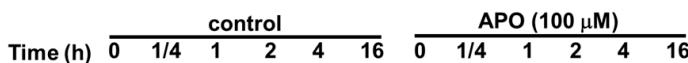

Pyk2 $\rightarrow \Rightarrow$ L

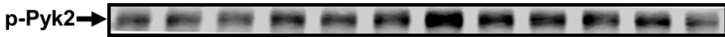

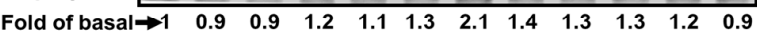

control

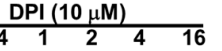

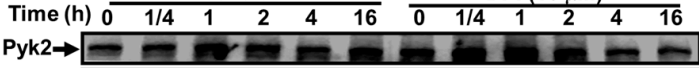

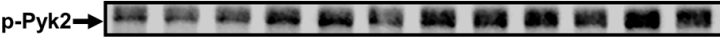

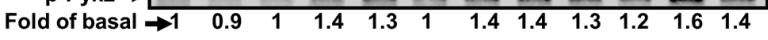

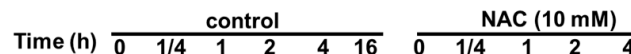

Pyk $\Rightarrow$\begin{tabular}{llllllllllll}
0 & $1 / 4$ & 1 & 2 & 4 & 16 & 0 & $1 / 4$ & 1 & 2 & 4 & 16 \\
\hline & & & & & & & & & & &
\end{tabular}

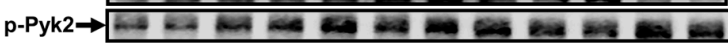

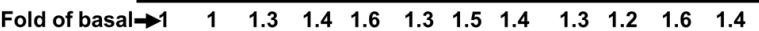

Figure 5. Proline-rich tyrosine kinase 2 (Pyk2) is involved in CORM-2-induced HO-1 expression in HTSMCs. (A) Cells were pretreated with PF431396 for $1 \mathrm{~h}$, and then incubated with CORM-2 for $24 \mathrm{~h}$. The protein levels of HO- 1 and $\beta$-actin (served as an internal control) were determined by western blot. (B) Cells were pretreated with PF431396 $(10 \mu \mathrm{M})$ for $1 \mathrm{~h}$, and then incubated with CORM-2 for $6 \mathrm{~h}$. The mRNA expression of HO-1 was determined by real-time PCR. (C) Cells were transfected with either scrambled (Scrb) or Pyk2 siRNA, and then incubated with CORM-2 for $24 \mathrm{~h}$. The levels of Pyk2, HO-1, and $\beta$-actin (served as an internal control) protein were determined by Western blot. (D) Cells were pretreated without or with PF431396 $(10 \mu \mathrm{M})$, APO $(100 \mu \mathrm{M})$, DPI $(10 \mu \mathrm{M})$, or NAC $(10 \mathrm{mM})$ for $1 \mathrm{~h}$, and then incubated with CORM-2 for the indicated time intervals. The levels of phospho-Pyk2 and Pyk2 (served as an internal control) were determined by Western blot. Data are expressed as mean \pm SEM of five independent experiments $(n=5)$. ${ }^{\#} p<0.05$, as compared with the cells exposed to CORM-2 alone. Data analysis and processing are described in the section "Statistical Analysis of Data".

\subsection{Involvement of ERK1/2 in CORM-2-Induced HO-1 Expression}

We have previously demonstrated that MAPKs participate in the HO-1 induction by LTA and CSPE in HTSMCs [20]. Therefore, we further approached the roles of p42/p44 MAPK in CORM-2-induced $\mathrm{HO}-1$ expression in these cells. We found that pretreatment with a MEK1/2 inhibitor (U0126) significantly blocked HO-1 protein and mRNA expressions (Figure 6A,B), which were both CORM-2-induced. To further ensure the role of p42/p44 MAPK in CORM-2-induced HO-1 expression, transfection with p44 siRNA markedly knocked down the p44 protein level and blocked the CORM-2-induced HO-1 expression (Figure 6C). To confirm whether p42/p44 MAPK phosphorylation is necessary for CORM-2-induced HO-1 expression, activation of the kinases was assayed by Western blot using an antibody specific for the phosphorylated form of p42/p44 MAPK. As shown in Figure 6D, CORM-2 stimulated a time-dependent phosphorylation of p42/p44 MAPK, which was inhibited by pretreatment with U0126 (10 $\mu \mathrm{M})$ during the period of observation. Further, pretreatment with Gö6983, PF431396, NAC, DPI, or APO significantly attenuated CORM-2-stimulated p42/p44 MAPK phosphorylation (Figure 5D), indicating that p42/p44 MAPK was a downstream component of PKC $\alpha$, which is a 
Pyk2-mediated Nox/ROS generation pathway. Our findings demonstrated that CORM-2-induced HO- 1 expression is mediated through the activation of the PKC $\alpha$, Pyk2/Nox/ROS/p42/p44 MAPK pathway in HTSMCs.
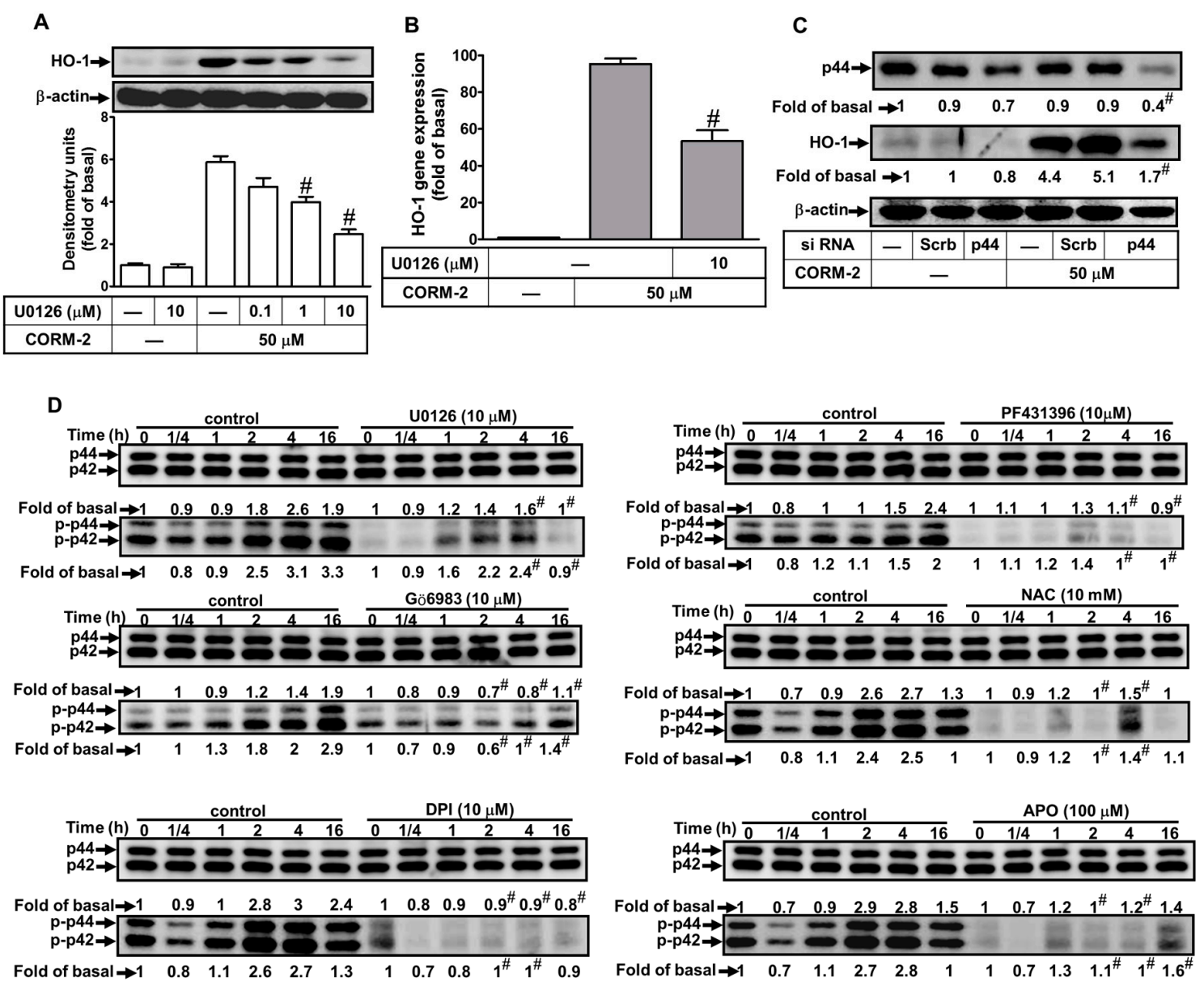

Figure 6. CORM-2-induced HO-1 expression is mediated through extracellular signal-regulated kinase 1/2 (ERK1/2) in HTSMCs. (A) Cells were pretreated with U0126 for $1 \mathrm{~h}$, and then incubated with CORM-2 for $24 \mathrm{~h}$. The protein levels of HO-1 and $\beta$-actin (served as an internal control) were determined by Western blot. (B) Cells were pretreated with U0126 $(10 \mu \mathrm{M})$ for $1 \mathrm{~h}$, and then incubated with CORM-2 for $6 \mathrm{~h}$. The mRNA expression of HO-1 was determined by real-time PCR. (C) Cells were transfected with either scrambled (Scrb) or p44 siRNA, and then incubated with CORM-2 for $24 \mathrm{~h}$. The levels of p44 and HO-1 protein were determined by Western blot. (D) Cells were pretreated with or without U0126 $(10 \mu \mathrm{M})$, Gö6983 $(10 \mu \mathrm{M})$, PF431396 $(10 \mu \mathrm{M})$, NAC $(10 \mathrm{mM})$, DPI $(10 \mu \mathrm{M})$, or APO $(100 \mu \mathrm{M})$, and then incubated with CORM-2 for the indicated time intervals. The levels of phospho-p42/p44 MAPK and p42/p44 MAPK (served as an internal control) were determined by Western blot. Data are expressed as mean \pm SEM of five independent experiments $(n=5)$. ${ }^{\#} p<0.05$, as compared with the cells exposed to CORM-2 alone. Data analysis and processing are described in the section "Statistical Analysis of Data".

\subsection{Induction of c-Fos and c-Jun/AP-1 is Required for CORM-2-Induced HO-1 Expression}

Moreover, AP-1 has been shown to regulate HO-1 expression through binding to respective elements in the promoter region in response to oxidative stress [38,39]. Hence, we determined whether CORM-2-induced HO-1 expression was mediated via AP-1 using its inhibitor tanshinone IIA (TSIIA). As shown in Figure 7A,B, pretreatment with TSIIA attenuated CORM-2-induced HO-1 protein and mRNA expression, suggesting that in HTSMCs, activated AP- 1 is an important event for CORM-2-induced HO-1 expression. To further approach the roles of c-Fos and c-Jun in CORM-2-induced HO-1 expression, transfection with either c-Fos or c-Jun siRNA significantly knocked down the c-Fos 
or c-Jun protein expression, respectively, and attenuated HO-1 induction in CORM-2-treated HTSMCs (Figure 7C). To study whether CORM-2 accelerated AP-1 transcription activity, a reporter plasmid construct containing the AP-1 response element was used to evaluate AP-1 activity in HTSMCs. We found that CORM-2 stimulated a time-dependent AP-1 promoter activity (Figure 7D), which was inhibited by pretreatment with Gö6983, PF431396, NAC, DPI, APO, U0126, or TSIIA (Figure 7E). These results suggested that $\mathrm{HO}-1$ induction is mediated via PKC $\alpha$, Pyk2/Nox/ROS/p42/p44 MAPK-dependent activation of AP-1(c-Fos/c-Jun) in CORM-2-treated HTSMCs.
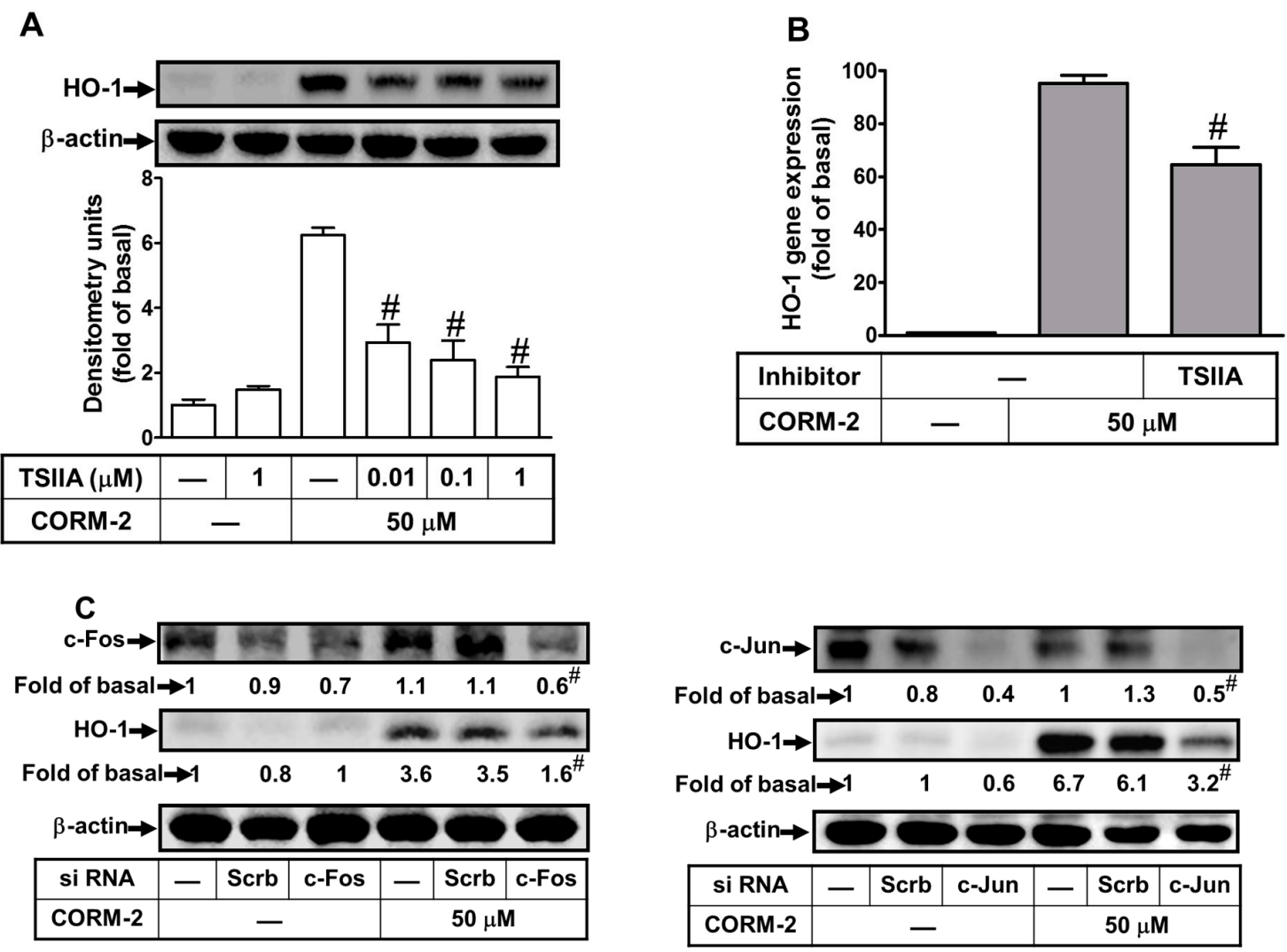

D

E
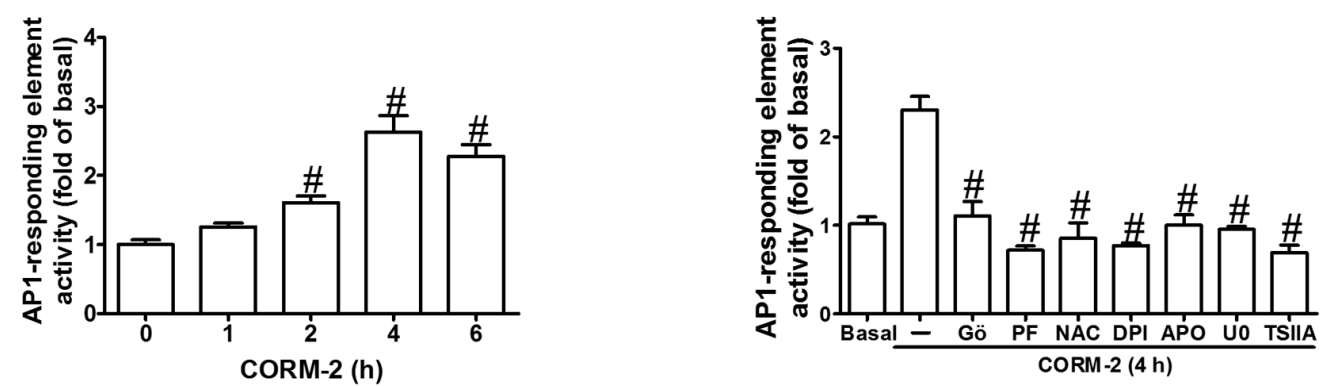

Figure 7. Involvement of c-Fos and c-Jun/activator protein 1 (AP-1) in CORM-2-mediated HO-1 expression. (A) Cells were pretreated with tanshinone IIA (TSIIA) for $1 \mathrm{~h}$, and then incubated with CORM-2 for $24 \mathrm{~h}$. The protein levels of HO- 1 and $\beta$-actin (served as an internal control) were determined by Western blot. (B) Cells were pretreated with TSIIA $(1 \mu \mathrm{M})$ for $1 \mathrm{~h}$, and then incubated with CORM-2 for $6 \mathrm{~h}$. The mRNA expression of HO-1 was determined by real-time PCR. (C) Cells were transfected with either scrambled (Scrb), c-Fos, or c-Jun siRNA, and then incubated with CORM-2 for $24 \mathrm{~h}$. The levels of c-Fos, c-Jun, HO-1, and $\beta$-actin (served as an internal control) protein were determined by Western blot. (D) Cells were transiently cotransfected with pAP1-Luc (activator protein-1 luciferase reporter plasmid) and pGal (plasmid contains the reporter gene $\beta$-galactosidase) for $24 \mathrm{~h}$, and then incubated with CORM-2 for the indicated time intervals. (E) Cells were pretreated with Gö6983 $(10 \mu \mathrm{M})$, 
PF431396 (10 $\mu \mathrm{M})$, N-acetyl-cysteine (NAC, $10 \mathrm{mM})$, DPI $(10 \mu \mathrm{M})$, APO (100 $\mu \mathrm{M})$, U0126 (10 $\mu \mathrm{M})$, or TSIIA $(1 \mu \mathrm{M})$ for $1 \mathrm{~h}$ and then incubated with CORM- 2 for $4 \mathrm{~h}$. The AP-1 promoter activity in the cell lysates was determined as described in the Methods section. Data are expressed as mean \pm SEM of five independent experiments $(n=5) .{ }^{\#} p<0.05$, as compared with the cells exposed to vehicle (D) or CORM-2 (A-C,E) alone. Data analysis and processing are described in the section "Statistical Analysis of Data".

\subsection{CORM-2 Induces HO-1 Expression via Its Promoter Transcriptional Activity}

CORM-2 has been shown to induce HO-1 gene regulation and activate the AP-1 activity. Thus, human HO-1 promoter was constructed in a luciferase reporter plasmid to evaluate the CORM-2 induced HO-1 transcription in HTSMCs. The HO-1 promoter contains several putative recognition elements for a variety of transcriptional factors, including the AP-1 site. As expected, CORM-2 stimulated the HO-1 promoter activity in a time-dependent manner with a maximal response within 6 h (Figure 8A), which was inhibited by pretreatment with Gö6983, PF431396, NAC, DPI, APO, U0126, or TSIIA (Figure $8 \mathrm{~B}$ ). These results confirmed that CORM-2 stimulates HO-1 promoter activity via AP-1 activation, which was mediated through PKC $\alpha$ or Pyk2-regulated Nox/ROS/p42/p44 MAPK-dependent c-Fos-c-Jun/AP-1 pathway in HTSMCs.
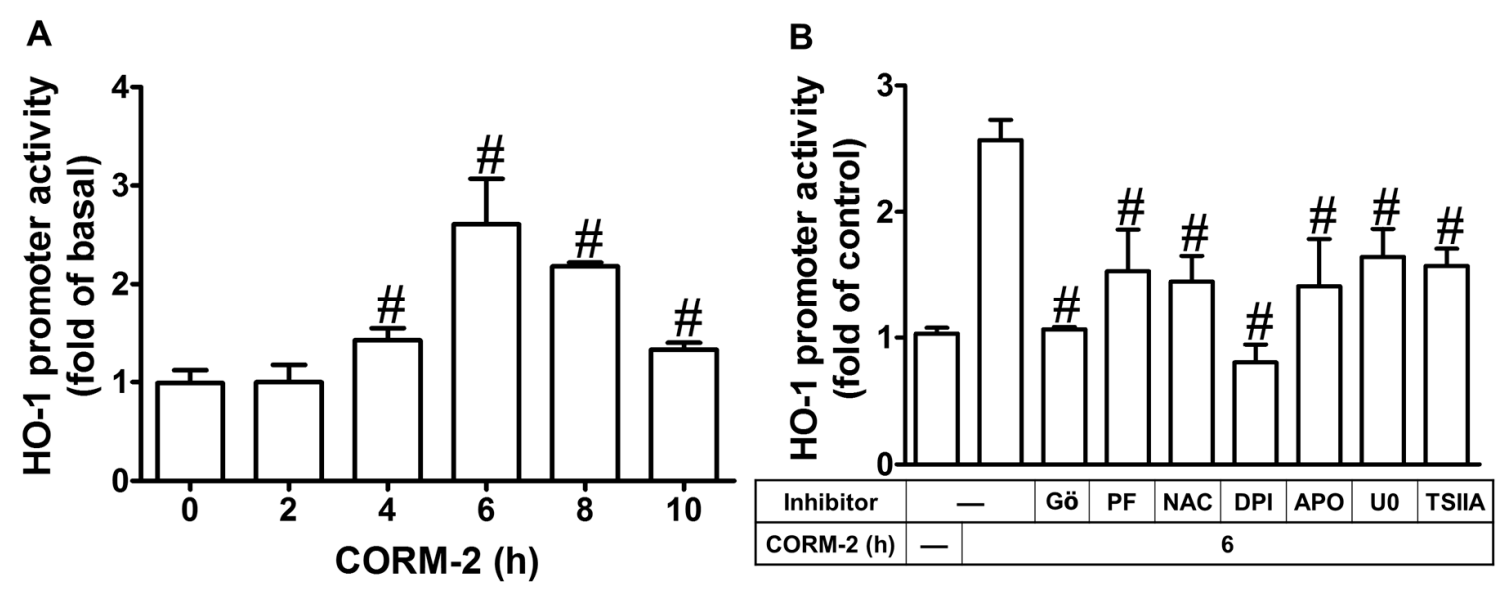

Figure 8. CORM-2 induces AP-1-dependent HO-1 expression via PKC $\alpha / \mathrm{Pyk} 2 / \mathrm{Nox} / \mathrm{ROS} / \mathrm{ERK}$ pathway in HTSMCs. (A) Cells were transiently cotransfected with pHO1-Luc and pGal for $24 \mathrm{~h}$, and then incubated with CORM-2 $(50 \mu \mathrm{M})$ for the indicated time intervals. (B) Cells were pretreated with Gö6983 (10 $\mu \mathrm{M})$, PF431396 (10 $\mu \mathrm{M})$, NAC (10 mM), DPI $(10 \mu \mathrm{M})$, APO $(100 \mu \mathrm{M})$, U0126 $(10 \mu \mathrm{M})$, or TSIIA $(10 \mu \mathrm{M})$ for $1 \mathrm{~h}$ and then incubated with CORM-2 for $6 \mathrm{~h}$. The HO-1 promoter activity in the cell lysates was determined. Data are expressed as mean \pm SEM of five independent experiments $(n=5) .{ }^{\#} p<0.05$, as compared with the cells exposed to vehicle (A) or CORM-2 alone. Data analysis and processing are described in the section "Statistical Analysis of Data".

\section{Discussion}

CORMs exert anti-inflammatory effects through the up-regulation of anti-oxidant enzymes such as HO-1 [26]. However, the roles of Nox/ROS involved in CORM-2-induced HO-1 expression were still unknown. Here, we observed that pretreatment with CORM-2 inhibited the LPS-induced airway inflammation via HO-1 induction in mice. Further, our results demonstrated that the levels of HO-1 protein, mRNA, and promoter activity were increased in HTSMCs challenged with CORM-2. CORM-2-induced HO-1 expression was mediated through PKC $\alpha$ and Pyk2/Nox/ROS/ERK1/2 linking to the AP-1 pathway in HTSMCs (Figure 9). These results suggested that HO-1 expression induced by CORM-2 is mediated via a PKC $\alpha$ and Pyk2/Nox/ROS/p42/p44 MAPK-dependent AP-1 pathway in HTSMCs. 


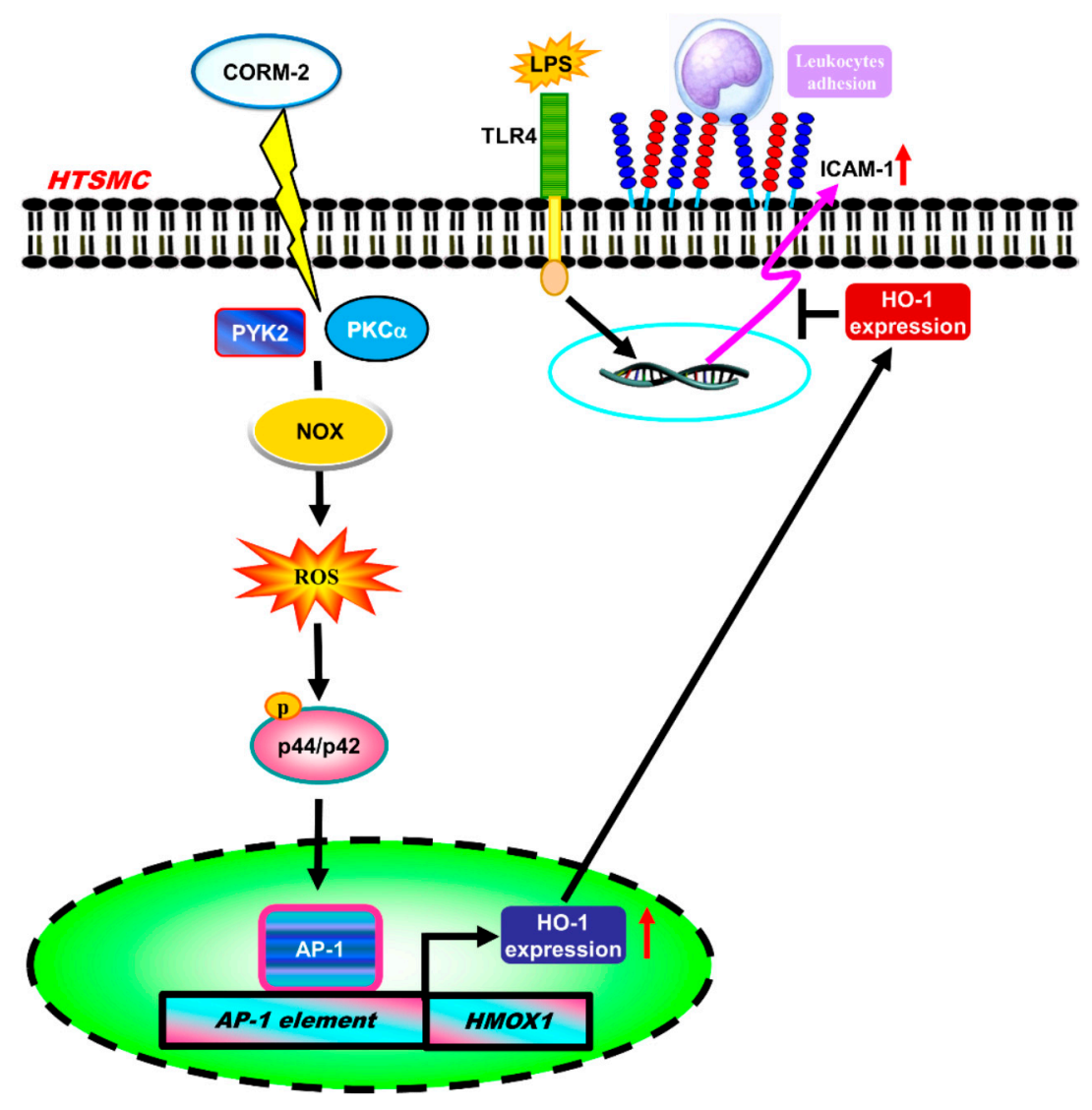

Figure 9. Schematic signaling pathways are involved in CORM-2-induced HO-1 expression in HTSMCs. CORM-2-induced HO-1 expression is mediated via a PKC $\alpha$ or Pyk2/Nox/ROS/ERK1/2 cascade linking to activation of c-Fos and c-Jun/AP-1. The up-regulation of HO-1 could protect against the LPS-induced airway inflammation.

ROS exert as a messenger in the normal physiological functions and the inflammatory responses dependent on their cellular concentrations [40]. The up-regulation of HO-1 due to Nox activity and ROS formation is induced by LPS and cytokines [8,19]. Others and our previous studies indicated that the CORMs mediate Nox-dependent ROS generation in astrocytes [21,22]. Therefore, Nox-dependent ROS generation is involved in HO-1 expression by CORM-2 in HTSMCs. We further clarified the role of ROS in HO-1 expression; a thiol-containing compound (NAC) was used to scavenge ROS. NAC has been shown to reduce the injurious effects of hydrogen peroxide in human alveolar and bronchial epithelial cells [41]. We also found that CORM-2-induced HO-1 expression was inhibited by NAC, and strongly supported the role of ROS in the CORM-2-induced HO-1 expression.

Moreover, two Nox-related inhibitors, DPI (a Nox inhibitor) and APO (a p47phox inhibitor), have been shown to prevent $\mathrm{p} 47^{\text {phox }}$ (a Nox subunit) translocation to the membrane and inhibit Nox activation [42]. Our results showed that pretreatment with either DPI or APO attenuated CORM-2induced ROS generation and HO-1 expression. These data are consistent with previous reports showing that Nox-derived ROS generation is involved in HO-1 induction by LTA or CSPE in HTSMCs $[5,20]$. Indeed, low levels of ROS could regulate proliferation, gene expression, immunity, and wound healing [43]. Conversely, higher levels of ROS can exert antibacterial effect, and cause cell damage and death $[23,44]$. In addition, ROS generation could initiate HO-1 expression through the degradation of Keap1 and translocation of Nrf2 into the nucleus. In our previous study, CORM-2 has been shown to activate Nox and produce ROS in brain astrocytes [22]. Previous reports also indicate that CO release in mammal cells acts as a secondary messenger to mediate metabolism and gene expression, including HO-1 $[45,46]$. The members of Nox family such as Nox- $(1,2,4)$ and $p 47^{\text {phox }}$ were shown to be involved in CORM-2-induced HO-1 expression, which were confirmed by using their own siRNAs. In this 
study, we also demonstrated that PKC $\alpha$ and Pyk2 are the upstream components of ROS generation

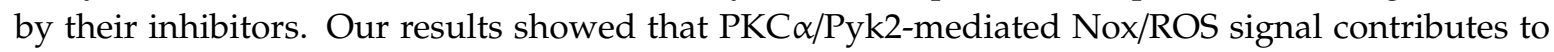
CORM-2-induced HO-1 expression in HTSMCs. However, how CORM-2 activated PKC $\alpha /$ Pyk2 and led to Nox/ROS generation is an important issue preserved for further investigation.

Abnormal MAPK activations are implicated in a variety of inflammatory responses and tissue injury, and the induction of several inflammatory mediators in different cell types [25,47]. Here, we demonstrated that ERK1/2 was required for the CORM-2-induced HO-1 expression, which was attenuated by a selective MEK1/2 inhibitor U0126 or transfection with p44 siRNA. These kinases involved in CORM-2-stimulated pathways were further confirmed by CORM-2-mediated ERK1/2 phosphorylation. These results are consistent with the HO- 1 expression mediated by ERK1/2 to activate the antioxidant response element (ARE) region, which is the Nrf2 binding site in HepG2 (liver hepatocellular carcinoma) Cells [48] and heme-mediated neuronal injury [49]. Moreover, pretreatment with the inhibitor of PKC $\alpha$, Pyk2, Nox, or ROS scavenger significantly attenuated ERK1/2 phosphorylation, suggesting that PKC $\alpha /$ Pyk2-dependent Nox/ROS are required for ERK1/2 phosphorylation. These results are consistent with reports that ROS-dependent MAPK pathways are involved in the regulation of cellular functions [38,50,51]. Indeed, our previous study found that the inhibition of JNK1/2 or p38 MAPK attenuates CORM-2-induced HO-1 expression via a c-Src/EGFR/PI3K/Akt pathway [27]. In contrast, CORM-2-stimulated JNK1/2 and p38 MAPK phosphorylation was not mediated via the PKC $\alpha /$ Pyk2-mediated Nox/ROS signal, although these two kinases also regulate CORM-2-induced HO-1 expression in HTSMCs.

The activated transcription factors interact with response elements on the HO-1 promoter to regulate gene transcription [44]. Here, we focused on the role of transcription factor AP-1, which is modulated during oxidative stress associated with inflammatory diseases [52]. The involvement of AP-1 in these responses was further supported by the results that CORM-2 induced c-Fos and c-Jun,

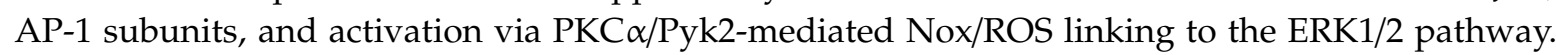
Moreover, the roles of c-Fos-c-Jun/AP-1 in CORM-2-induced HO-1 expression were confirmed by transfection with c-Fos or c-Jun siRNA to attenuate CORM-2-induced HO-1 expression. Several reports have shown that many regulatory elements of transcription factors, including AP-1, were analyzed on the $5^{\prime}$ region of the HO-1 promoter in several animal species $[28,53]$. Thus, we also demonstrated that CORM-2-stimulated HO-1 promoter activity was reduced by pretreatment with Gö6976, PF431396, NAC, DPI, APO, U0126, or TSIIA, indicating that CORM-2 induces HO-1 promoter activity via a PKC $\alpha / P y k 2-m e d i a t e d$ Nox/ROS/ERK1/2/AP-1 pathway. These results are consistent with the reports that alpha-lipoic acid induced HO-1 expression in vascular smooth muscle cells [54], and BK induced HO-1 expression in brain astrocytes [38].

Previous reports indicated that the CORMs up-regulate the HO-1 activity and attenuate the LPS-induced inflammatory responses in macrophages [9] and animal study [8,31]. Moreover, the overexpression of HO-1 in ovalbumin (OVA)-sensitized guinea pigs effectively decreases inflammatory reaction, mucus secretion, and responsiveness to histamine in airways [55], suggesting that HO-1 exhibits protecting ability in the host during airway inflammation. In this study, the induction of HO-1 by CORM-2 protected against LPS-induced ICAM-1 expression and leukocytes infiltration in both in vitro and in vivo studies. Importantly, previous reports also indicated that CORM-2-derived $\mathrm{CO}$ release can attenuate the cell sequestration, NF- $\mathrm{KB}$ activity, and ICAM-1 expression of leukocyte after lung injury $[36,56]$ and regulate the expressions of adhesion molecules on human umbilical vein endothelia cells to affect leukocyte attachment [54]. Our previous report also indicated that the induction of HO- 1 by CoPPIX inhibits the TNF- $\alpha$-induced ICAM- 1 and VCAM- 1 expression which is revered by zinc protoporphyrin IX (ZnPPIX, an inhibitor of HO-1 activity) in HTSMCs [14]. 


\section{Materials and Methods}

\subsection{Reagents and Chemicals}

DMEM/F-12 (Dbecco's Modified Eagle Medium/Nutrient Mixture F-12) medium, fetal bovine serum (FBS), TRIzol reagent, and PLUS-Lipofectamine were from Invitrogen (Carlsbad, CA, USA). Human siRNAs for PKC $\alpha$ (L-003523-00-0020) was from Dharmacon (Lafayette, CO, USA) and Pyk2 (SASI_Hs01_00032249), ERK1 (SASI_Hs01_00190617), HO-1 (SASI_Hs01_00035065), Nox-1 (SASI_Hs01_00342845), Nox-2 (SASI_Hs01_00086110), Nox-4 (SASI_Hs02_00349918), p47 phox (SASI_Hs02_00302212), and c-Fos (SASI_Hs01_00184572) were from Sigma (St. Louis, MO, USA). Hybond C membrane, enhanced chemiluminescence (ECL), and Western blotting detection system were from GE Healthcare Biosciences (Buckinghamshire, UK). PhosphoPlus PKC $\alpha$ (\#9375), Pyk2 (\#3291), and ERK1/2 (\#9101) antibodies were from Cell Signaling (Danvers, MA, USA). The HO-1 (ADI-SPA-895) antibody was from Enzo (Farmingdale, NY, USA). PKC $\alpha$ (sc-208), Pyk2 (sc-9019), ERK1 (sc-94), c-Fos (sc-7202), and $\beta$-actin (sc-47778) antibodies were from Santa Cruz (Santa Cruz, CA, USA). Ro31-8220, Gö6983, Gö6976, PF431396, diphenyleneiodonium chloride (DPI), apocynin (APO), U0126, and tanshinone IIA (TSIIA) were from Biomol (Plymouth Meeting, PA, USA). The bicinchoninic acid (BCA) protein assay kit was from Pierce (Rockford, IL, USA). SDS-PAGE (sodium dodecyl sulfate polyacrylamide gel electrophoresis) reagents were from MDBio Inc (Taipei, Taiwan). Tricarbonyldichlororuthenium (II) dimer (CORM-2), ruthenium (III) chloride, $\mathrm{RuCl}_{3}$ [inactive form of CORM-2, (iCORM-2)], N-acetyl-cysteine (NAC), lipopolysaccharide (LPS), enzymes, and other chemicals were from Sigma (St. Louis, MO, USA).

\subsection{Animal Care and Experimental Procedures}

Male ICR mice aged 6-8 weeks were purchased from the National Laboratory Animal Centre (Taipei, Taiwan) and handled according to the guidelines of Animal Care Committee of Chang Gung University (Approval Document No. Chang Gung University 16-046, 4 October 2016) and National Institute of Health (NIH) Guides for the Care and Use of Laboratory Animals. All the studies involving animals are reported in accordance with the ARRIVE guidelines $[57,58]$. Mice were assigned randomly into three groups: sham [0.1 mL of dimethyl sulfoxide (DMSO)-phosphate-buffered saline (PBS) (1:100) with $0.1 \%(w / v)$ bovine serum albumin (BSA) treated mice], LPS (LPS-treated mice), and CORM-2 + LPS; 5 mice in each group/cage and kept in standard individually ventilated cages in an animal facility under standardized conditions ( $12 \mathrm{~h}$ light/dark cycle, $21-24{ }^{\circ} \mathrm{C}$, humidity of 50-60\%) with food and water ad libitum. Mice were intraperitoneally (i.p.) injected with CORM-2 ( $8 \mathrm{mg} / \mathrm{kg}$ of body weight) for $24 \mathrm{~h}$, and then anesthetized by i.p. injection of pentothal $(50 \mathrm{mg} / \mathrm{kg})$ placed individually on a board in a near-vertical position and the tongues withdrawn with a lined forceps. LPS $(3 \mathrm{mg} / \mathrm{kg}$ ) was placed posterior in the throat and aspirated into lungs for $16 \mathrm{~h}$ of development of a lung inflammation model [59]. At the end of the experimental period, mice were killed by a high dose of pentothal (100 mg/kg i.p.) for the collection of lung tissues extracted for protein (right superior lobe + post caval lobe) and mRNA (right middle lobe + right inferior lobe) expression of ICAM-1, HO-1, or $\beta$-actin analyses. BAL fluid was performed through a tracheal cannula using 1-mL aliquots of ice-cold PBS solution. BAL fluid was centrifuged at $500 \times g$ at $4{ }^{\circ} \mathrm{C}$, and cell pellets were washed and re-suspended in PBS. Leukocyte count was determined by a hemocytometer, as previously described [7]. Data collection and evaluation of all the in vivo and in vitro experiments were performed blindly of the group identity.

\subsection{Cell Culture and Treatment}

HTSMCs were purchased from ScienCell Research Laboratories (San Diego, CA, USA). The cultured conditions and treatments were conducted as previously described [60]. Cells were plated onto 12-well culture plates and made quiescent at confluence by incubation in serum-free DMEM/F-12 for $24 \mathrm{~h}$. Growth-arrested cells were incubated with or without CORM-2 at $37^{\circ} \mathrm{C}$ for the indicated time 
intervals. Our previous report indicates that CORM-2 induces HO-1 expression in time-dependent and concentration-dependent manners. The HO- 1 expression is up-regulated to a maximal response within 16-24 h treatment with $50 \mu \mathrm{M}$ of CORM-2 [27]. Therefore, the concentration of CORM-2 at $50 \mu \mathrm{M}$ was used throughout this study. When the inhibitors were used, cells were pretreated with the inhibitor for $1 \mathrm{~h}$ before exposure to CORM-2. Experiments were performed using cells from passages four to seven.

\subsection{Preparation of Cell Extracts and Western Blot Analysis}

After treatment, the cells were washed with ice-cold PBS, scraped, and collected by centrifugation at $16,000 \times g$ for $10 \mathrm{~min}$ at $4{ }^{\circ} \mathrm{C}$ to yield the whole cell extract, as previously described [7]. The supernatants were harvested and mixed with SDS-PAGE loading buffer (final concentration: $100 \mathrm{mM}$ Tris-HCl pH 6.8, 1\% SDS, 2.5\% glycerol, $100 \mathrm{mM} \beta$-mercaptoethanol, $0.01 \%$ bromophenol blue). Samples were denatured, separated with $10 \%$ SDS-PAGE, and transferred to the nitrocellulose membrane. Membranes were probed overnight with an anti-phospho-PKC $\alpha$, phospho-Pyk2, phospho-ERK1/2, HO-1, PKC $\alpha$, Pyk2, ERK1, c-Fos, or $\beta$-actin antibody. Membranes were washed with Tween-Tris buffered solution (TTBS) four times for $5 \mathrm{~min}$ each, incubated with anti-rabbit or anti-mouse horseradish peroxidase antibody (1:2000) for $1 \mathrm{~h}$. The immunoreactive bands were detected by ECL (enhanced chemiluminescence) reagents and captured by a UVP BioSpectrum 500 Imaging System (Upland, CA, USA). The image densitometry analysis was conducted using UN-SCAN-IT gel software (Orem, UT, USA).

\subsection{Total RNA Extraction and Real Time-Quantitative PCR Analysis}

Total RNA was isolated from HTSMCs treated with CORM-2 for the indicated time intervals in 10-cm culture dishes with TRIzol according to the protocol of the manufacturer. The mRNA was reverse-transcribed into cDNA and analyzed by real time-quantitative (q)PCR. Real time-qPCR was performed with the TaqMan gene expression assay system, using primers and probe mixes for HO-1, c-Fos, and endogenous GAPDH control genes. PCRs were performed using a 7500 Real Time-PCR System (Applied Biosystems, Foster City, CA, USA). Relative gene expression was determined by the $\Delta \Delta \mathrm{Ct}$ method, where $\mathrm{Ct}$ meant threshold cycle. All the experiments were performed in triplicate.

\subsection{Plasmid Construction, Transfection, and Luciferase Reporter Gene Assays}

For construction of the HO-1 luciferase (Luc) plasmid, human HO-1 promoter, a region spanning -3106 to +186 bp provided by Dr. Y. C. Liang (Graduate Institute of Biomedical Technology, Taipei Medical University, Taipei, Taiwan) was inserted into a pGL3-basic vector (Promega, Madison, WI, USA). Plasmid pAP1-Luc, the fragment of the AP-1-responding element was inserted into the pGL3 (plasmid contains the reporter gene $\beta$-galactosidase) promoter. The plasmid DNA was extracted by using QIAGEN plasmid DNA preparation kits and transfected into HTSMCs with Lipofectamine reagent according to the standard protocol of the manufacturer. The plasmid pCMV- $\beta$-gal was cotransfected to be the internal control. The HO-1 promoter-driven-Luc activity was analyzed by a luciferase assay system (Promega, Madison, WI, USA). Firefly luciferase activities were standardized with $\beta$-galactosidase activity.

\subsection{Transient Transfection with siRNAs}

HTSMCs $\left(3 \times 10^{5}\right.$ cells) were plated in 12 -well culture plates for $24 \mathrm{~h}$ to about $80 \%$ confluence. Cells were washed once with PBS, and $0.4 \mathrm{~mL}$ of serum-free DMEM/F-12 medium was added to each well. The transient transfection of siRNAs (scrambled, PKC $\alpha$, Pyk2, ERK1, and c-Fos, $100 \mathrm{nM}$ ) was performed by using Lipofectamine ${ }^{\mathrm{TM}}$ RNAiMAX reagent (from Sigma, St. Louis, MO, USA) according to the manufacturer's instructions. 


\subsection{Measurement of Intracellular ROS Generation}

The peroxide-sensitive fluorescent probe $\mathrm{CMH}_{2}$ DCF-DA and DHE were used to assess the intracellular ROS generation [61] with minor modifications. Briefly, HTSMCs were incubated with $10 \mu \mathrm{M}$ of $\mathrm{CMH}_{2} \mathrm{DCF}-\mathrm{DA}$ (in warm PBS) for $45 \mathrm{~min}$ at $37^{\circ} \mathrm{C}$. The medium was removed and replaced with fresh DMEM/F-12 media for CORM-2 treatments. $\mathrm{CMH}_{2}$ DCF-DA interacted with cells, and then generated a non-fluorescent product: $\mathrm{H}_{2}$ DCF. CORM-2 induced the generation of a ROS oxidized product: DCF. Relative fluorescence intensity was recorded ( 0.5 to $24 \mathrm{~h}$ ) by a fluorescent plate reader (Thermo, Appliskan; Waltham, MA, USA) at an excitation wavelength of $485 \mathrm{~nm}$, and emission was measured at a wavelength of $530 \mathrm{~nm}$. For DHE staining, cells were treated with CORM-2 for the indicated time intervals and then incubated with $10 \mu \mathrm{M}$ of DHE (in DMEM/F12 medium) for $10 \mathrm{~min}$. For immunofluorescence staining, the stained cells were washed three times with cold PBS, and then the fluorescence for DCF and DHE staining was detected at 495/529 and 518/605 nm, respectively, using a fluorescence microscope (Zeiss, Axiovert 200M; Oberkochen, Baden-Württemberg, Germany).

\subsection{Determination of NADPH Oxidase Activity by Chemiluminescence Assay}

The Nox activity in intact cells was assayed by lucigenin chemiluminescence [38]. After incubation, the cells were gently scraped and centrifuged at $400 \times \mathrm{g}$ for $10 \mathrm{~min}$ at $4{ }^{\circ} \mathrm{C}$. The cell pellet was re-suspended in a known volume (35 $\mu \mathrm{L} /$ well) of ice-cold RPMI 1640 medium, and the cell suspension was kept on ice. To a final $200 \mu \mathrm{L}$ of pre-warmed $\left(37^{\circ} \mathrm{C}\right)$ PBS containing either NADPH $(1 \mu \mathrm{M})$ or lucigenin $(20 \mu \mathrm{M}), 5 \mu \mathrm{L}$ of cell suspension $\left(2 \times 10^{4}\right.$ cells) was added to initiate the reaction followed by the immediate measurement of chemiluminescence using an Appliskan luminometer (Thermo ${ }^{\circledR}$; Waltham, MA, USA) in an out-of-coincidence mode. Neither NADPH nor NADH enhanced the background chemiluminescence of lucigenin alone (30-40 counts/min). Chemiluminescence was continuously measured for $12 \mathrm{~min}$, and the activity of Nox was expressed as counts per million cells. The calculated numbers of Nox activity were calibrated with protein concentration. The equal amount of warmed PBS medium (containing NADPH and lucigenin) was used as the blank, and the untreated cells were the basal group.

\subsection{Statistical Analysis of Data}

All the data were expressed as the mean \pm SEM in at least five individual experiments $(n=5)$. Statistical analysis was performed by using GraphPad Prizm Program 6.0 software (GraphPad, San Diego, CA). We used one-way ANOVA followed by Dunnett's post hoc test when comparing more than two groups of data and a one-way ANOVA, non-parametric Kruskal-Wallis test, followed by Dunnett's post hoc test when comparing multiple independent groups. $p$ values of 0.05 were considered to be statistically significant. Post tests were run only if $\mathrm{F}$ achieved $p<0.05$ and there was no significant variance in homogeneity. Error bars were omitted when they fell within the dimensions of the symbols.

\section{Conclusions}

These results suggested that CORM-2-induced HO- 1 expression is mediated through PKC $\alpha / \mathrm{Pyk} 2$ and Nox/ROS-dependent activation of ERK1/2, linking to the up-regulation of AP-1 (c-Fos and c-Jun), which promotes HO-1 expression and enzymatic activity in HTSMCs. Based on the observations from literatures and our findings, we depict a model for the molecular mechanisms underlying CORM-2-induced HO-1 expression and activity in HTSMCs. The results obtained with cellular and animal experiments indicated that better understanding the mechanisms underlying CORM-2-induced $\mathrm{HO}-1$ expression promotes the development of therapeutic strategies for airway inflammatory disorders. 
Author Contributions: C.-C.L., L.-D.H., R.-L.C., and C.-M.Y. designed and conducted the study. C.-C.L., L.-D.H., and R.-L.C. performed and collected the data. C.-C.L., L.-D.H., R.-L.C., and C.-M.Y. analyzed and interpreted the data. C.-C.L. and C.-M.Y. prepared the manuscript. C.-C.L., L.-D.H., R.-L.C., and C.-M.Y. reviewed the manuscript. C.-C.L., L.-D.H., R.-L.C., and C.-M.Y. approved the final manuscript.

Funding: This work was supported by the Ministry of Education, Taiwan [grant number EMRPD1I0381]; the Ministry of Science and Technology, Taiwan [Grant numbers: MOST105-2320-B-182-005-MY3, MOST107-2320B-182-020-MY2, and MOST107-2320-B-182A-011]; Chang Gung Medical Research Foundation, Taiwan [Grant numbers: CMRPD1F0023, CMRPD1F0552, CMRPD1F0553, CMRPD1I0051-3, CMRPG3F1533, CMRPG3H0062, CMRPG3H0063, and CMRPG5F0203, CMRPG5I0041].

Acknowledgments: We appreciated Chen-yu Wang for his suggestions and construction of plasmids applied in this study and YC Tai for her technical assistance.

Conflicts of Interest: The authors declare no conflict of interest.

\begin{tabular}{|c|c|}
\hline AP-1 & activator protein 1 \\
\hline $\mathrm{APO}$ & apocynin \\
\hline ARE & antioxidant response element \\
\hline BAL & bronchoalveolar lavage \\
\hline BCA & bicinchoninic acid \\
\hline BSA & Bovine serum albumin \\
\hline $\mathrm{CO}$ & carbon monoxide \\
\hline CORM-2 & carbon monoxide releasing molecule- 2 \\
\hline CoPPIX & cobalt protoporphyrin \\
\hline CSPE & cigarette smoke particle extract \\
\hline DCF & dichlorofluorescein \\
\hline DCF-DA & $2^{\prime}, 7^{\prime}$-dichlorofluorescin diacetate \\
\hline DHE & dihydroethidium \\
\hline DMEM/F-12 & Dubecco's Modified Eagle Medium/Nutrient Mixture F-12 \\
\hline DMSO & dimethyl sulfoxide \\
\hline DPI & diphenyleneiodonium \\
\hline ECL & enhanced chemiluminescence \\
\hline EGFR & epidermal growth factor receptor \\
\hline ERK1/2 & extracellular signal-regulated kinase $1 / 2$ \\
\hline FBS & fetal bovine serum \\
\hline $\mathrm{MCH}_{2}$ DCF-DA & chloromethyl 2', $7^{\prime}$-dichloro fluorescein diacetate \\
\hline$H \& E$ & hematoxylin \& eosin \\
\hline $\mathrm{HO}-1$ & heme oxygenase- 1 \\
\hline HTSMCs & human tracheal smooth muscle cells \\
\hline ICAM-1 & intercellular adhesion molecule \\
\hline ICR & Institute of Cancer Research \\
\hline i.p. & intraperitoneally \\
\hline LPS & lipopolysaccharide \\
\hline LTA & lipotechoic acid \\
\hline MAPKs & mitogen-activated protein kinases \\
\hline mRNA & messenger ribonucleic acid \\
\hline NAC & $\mathrm{N}$-acetyl-cysteine \\
\hline NADPH & nicotinamaide adenine dinucleotide phosphate \\
\hline NF- $k B$ & nuclear factor- $\mathrm{kB}$ \\
\hline Nox & NADPH oxidase \\
\hline Nrf2 & nuclear factor erythroid 2-related factor 2 \\
\hline PBS & phosphate-buffered saline \\
\hline PI3K & phosphoinositide 3-kinase \\
\hline PKC & protein kinase $\mathrm{C}$ \\
\hline Pyk2 & proline-rich tyrosine kinase 2 \\
\hline ROS & reactive oxygen species \\
\hline
\end{tabular}




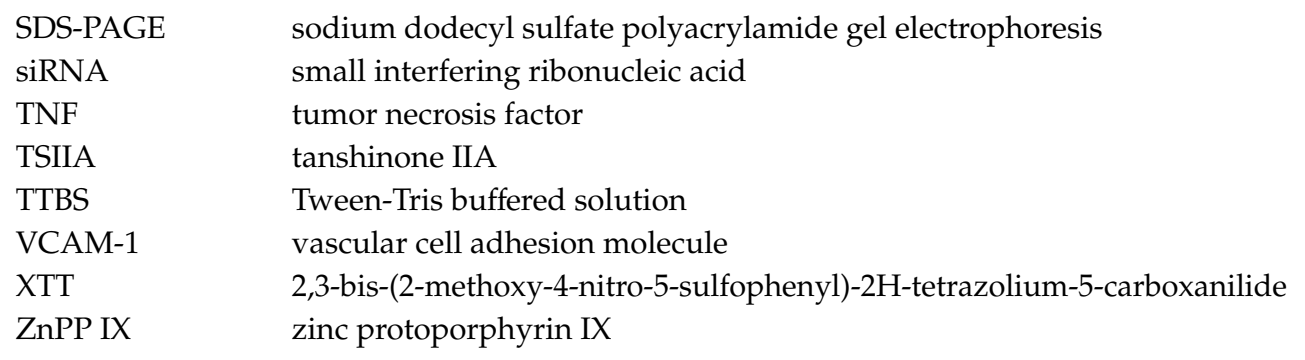

\section{References}

1. Maines, M.D. The heme oxygenase system: A regulator of second messenger gases. Annu. Rev. Pharmacol. Toxicol. 1997, 37, 517-554. [CrossRef]

2. Ryter, S.W.; Alam, J.; Choi, A.M. Heme oxygenase-1/carbon monoxide: From basic science to therapeutic applications. Physiol. Rev. 2006, 86, 583-650. [CrossRef] [PubMed]

3. Tenhunen, R.; Marver, H.S.; Schmid, R. The enzymatic conversion of heme to bilirubin by microsomal heme oxygenase. Proc. Natl. Acad. Sci. USA 1968, 61, 748-755. [CrossRef] [PubMed]

4. Otterbein, L.E.; Soares, M.P.; Yamashita, K.; Bach, F.H. Heme oxygenase-1: Unleashing the protective properties of heme. Trends Immunol. 2003, 24, 449-455. [CrossRef]

5. Lee, I.T.; Wang, S.W.; Lee, C.W.; Chang, C.C.; Lin, C.C.; Luo, S.F.; Yang, C.M. Lipoteichoic acid induces HO-1 expression via the TLR2/MyD88/c-Src/NADPH oxidase pathway and Nrf2 in human tracheal smooth muscle cells. J. Immunol. 2008, 181, 5098-5110. [CrossRef] [PubMed]

6. Balla, G.; Jacob, H.S.; Balla, J.; Rosenberg, M.; Nath, K.; Apple, F.; Eaton, J.W.; Vercellotti, G.M. Ferritin: A cytoprotective antioxidant strategem of endothelium. J. Biol. Chem. 1992, 267, 18148-18153. [PubMed]

7. Matsumoto, H.; Ishikawa, K.; Itabe, H.; Maruyama, Y. Carbon monoxide and bilirubin from heme oxygenase-1 suppresses reactive oxygen species generation and plasminogen activator inhibitor-1 induction. Mol. Cell. Biochem. 2006, 291, 21-28. [CrossRef]

8. Jamal Uddin, M.; Joe, Y.; Kim, S.K.; Oh Jeong, S.; Ryter, S.W.; Pae, H.O.; Chung, H.T. IRG1 induced by heme oxygenase-1/carbon monoxide inhibits LPS-mediated sepsis and pro-inflammatory cytokine production. Cell. Mol. Immunol. 2016, 13, 170-179. [CrossRef]

9. Sawle, P.; Foresti, R.; Mann, B.E.; Johnson, T.R.; Green, C.J.; Motterlini, R. Carbon monoxide-releasing molecules (CO-RMs) attenuate the inflammatory response elicited by lipopolysaccharide in RAW264.7 murine macrophages. Br. J. Pharmacol. 2005, 145, 8008-8010. [CrossRef]

10. Rushworth, S.A.; Chen, X.L.; Mackman, N.; Ogborne, R.M.; O'Connell, M.A. Lipopolysaccharide-induced heme oxygenase-1 expression in human monocytic cells is mediated via Nrf2 and protein kinase C. J. Immunol. 2005, 175, 4408-4415. [CrossRef]

11. Aggeli, I.K.; Gaitanaki, C.; Beis, I. Involvement of JNKs and p38-MAPK/MSK1 pathways in $\mathrm{H}_{2} \mathrm{O}_{2}$-induced upregulation of heme oxygenase-1 mRNA in H9c2 cells. Cell Signal. 2006, 18, 1801-1812. [CrossRef] [PubMed]

12. Fredenburgh, L.E.; Perrella, M.A.; Mitsialis, S.A. The role of heme oxygenase-1 in pulmonary disease. Am. J. Respir. Cell. Mol. Biol. 2007, 36, 158-165. [CrossRef]

13. Ferrandiz, M.L.; Devesa, I. Inducers of heme oxygenase-1. Curr. Pharm. Des. 2008, 14, 473-486. [CrossRef] [PubMed]

14. Lee, I.T.; Luo, S.F.; Lee, C.W.; Wang, S.W.; Lin, C.C.; Chang, C.C.; Chen, Y.L.; Chau, L.Y.; Yang, C.M. Overexpression of HO-1 protects against TNF-alpha-mediated airway inflammation by down-regulation of TNFR1-dependent oxidative stress. Am. J. Pathol. 2009, 175, 519-532. [CrossRef] [PubMed]

15. Lee, I.T.; Yang, C.M. Role of NADPH oxidase/ROS in pro-inflammatory mediators-induced airway and pulmonary diseases. Biochem. Pharmacol. 2012, 84, 581-590. [CrossRef] [PubMed]

16. Zuo, L.; Otenbaker, N.P.; Rose, B.A.; Salisbury, K.S. Molecular mechanisms of reactive oxygen species-related pulmonary inflammation and asthma. Mol. Immunol. 2013, 56, 57-63. [CrossRef] [PubMed]

17. Otterbein, L.E.; Kolls, J.K.; Mantell, L.L.; Cook, J.L.; Alam, J.; Choi, A.M. Exogenous administration of heme oxygenase-1 by gene transfer provides protection against hyperoxia-induced lung injury. J. Clin. Investig. 1999, 103, 1047-1054. [CrossRef] [PubMed] 
18. Li, F.J.; Duggal, R.N.; Oliva, O.M.; Karki, S.; Surolia, R.; Wang, Z.; Watson, R.D.; Thannickal, V.J.; Powell, M.; Watts, S.; et al. Heme oxygenase-1 protects corexit 9500A-induced respiratory epithelial injury across species. PLoS ONE 2015, 10, e0122275. [CrossRef] [PubMed]

19. Srisook, K.; Han, S.S.; Cho, H.S.; Li, M.H.; Ueda, H.; Kim, C.; Cha, Y.N. CO from enhanced HO activity or from CORM-2 inhibits both O2- and NO production and downregulates HO-1 expression in LPS-stimulated macrophages. Biochem. Pharmacol. 2006, 71, 307-318. [CrossRef]

20. Cheng, S.E.; Lee, I.T.; Lin, C.C.; Kou, Y.R.; Yang, C.M. Cigarette smoke particle-phase extract induces HO-1 expression in human tracheal smooth muscle cells: Role of the c-Src/NADPH oxidase/MAPK/Nrf2 signaling pathway. Free Radic. Biol. Med. 2010, 48, 1410-1422. [CrossRef]

21. Choi, Y.K.; Por, E.D.; Kwon, Y.G.; Kim, Y.M. Regulation of ROS production and vascular function by carbon monoxide. Oxid. Med. Cell. Longev. 2012, 2012, 794237. [CrossRef] [PubMed]

22. Chi, P.L.; Lin, C.C.; Chen, Y.W.; Hsiao, L.D.; Yang, C.M. CO Induces Nrf2-Dependent Heme Oxygenase-1 Transcription by Cooperating with Sp1 and c-Jun in Rat Brain Astrocytes. Mol. Neurobiol. 2015, 52, $277-292$. [CrossRef] [PubMed]

23. Taille, C.; El-Benna, J.; Lanone, S.; Boczkowski, J.; Motterlini, R. Mitochondrial respiratory chain and $\mathrm{NAD}(\mathrm{P}) \mathrm{H}$ oxidase are targets for the antiproliferative effect of carbon monoxide in human airway smooth muscle. J. Biol. Chem. 2005, 280, 25350-25360. [CrossRef] [PubMed]

24. Motterlini, R.; Green, C.J.; Foresti, R. Regulation of heme oxygenase-1 by redox signals involving nitric oxide. Antioxid. Redox Signal. 2002, 4, 615-624. [CrossRef] [PubMed]

25. Lee, I.T.; Yang, C.M. Inflammatory signalings involved in airway and pulmonary diseases. Mediat. Inflamm. 2013, 2013, 791231. [CrossRef] [PubMed]

26. Motterlini, R.; Otterbein, L.E. The therapeutic potential of carbon monoxide. Nat. Rev. Drug Discov. 2010, 9, 728-743. [CrossRef] [PubMed]

27. Yang, C.M.; Lin, C.C.; Lee, I.T.; Hsu, C.K.; Tai, Y.C.; Hsieh, H.L.; Chi, P.L.; Hsiao, L.D. c-Src-dependent transactivation of EGFR mediates CORM-2-induced HO-1 expression in human tracheal smooth muscle cells. J. Cell. Physiol. 2015, 230, 2351-2361. [CrossRef]

28. Alam, J.; Cook, J.L. How many transcription factors does it take to turn on the heme oxygenase-1 gene? Am. J. Respir. Cell Mol. Biol. 2007, 36, 166-174. [CrossRef]

29. Alam, J.; Stewart, D.; Touchard, C.; Boinapally, S.; Choi, A.M.; Cook, J.L. Nrf2, a Cap'n'Collar transcription factor, regulates induction of the heme oxygenase-1 gene. J. Biol. Chem. 1999, 274, 26071-26078. [CrossRef]

30. Constantin, M.; Choi, A.J.; Cloonan, S.M.; Ryter, S.W. Therapeutic potential of heme oxygenase-1/carbon monoxide in lung disease. Int. J. Hypertens. 2012, 2012, 859235. [CrossRef]

31. Xue, J.; Habtezion, A. Carbon monoxide-based therapy ameliorates acute pancreatitis via TLR4 inhibition. J. Clin. Investig. 2014, 124, 437-447. [CrossRef] [PubMed]

32. Qin, W.; Zhang, J.; Lv, W.; Wang, X.; Sun, B. Effect of carbon monoxide-releasing molecules II-liberated $\mathrm{CO}$ on suppressing inflammatory response in sepsis by interfering with nuclear factor kappa B activation. PLoS ONE 2013, 8, e75840. [CrossRef] [PubMed]

33. Takasuka, H.; Hayashi, S.; Koyama, M.; Yasuda, M.; Aihara, E.; Amagase, K.; Takeuchi, K. Carbon monoxide involved in modulating $\mathrm{HCO}_{3}{ }^{-}$secretion in rat duodenum. J. Pharmacol. Exp. Ther. 2011, 337, $293-300$. [CrossRef] [PubMed]

34. Wu-Zhang, A.X.; Newton, A.C. Protein kinase C pharmacology: Refining the toolbox. Biochem. J. 2013, 452, 195-209. [CrossRef] [PubMed]

35. Yang, C.C.; Lin, C.C.; Chien, P.T.; Hsiao, L.D.; Yan, C.M. Thrombin/Matrix Metalloproteinase-9-Dependent SK-N-SH Cell Migration is Mediated Through a PLC/PKC/MAPKs/NF-kappaB Cascade. Mol. Neurobiol. 2016, 53, 5833-5846. [CrossRef] [PubMed]

36. Mills, R.D.; Mita, M.; Nakagawa, J.; Shoji, M.; Sutherland, C.; Walsh, M.P. A role for the tyrosine kinase Pyk2 in depolarization-induced contraction of vascular smooth muscle. J. Biol. Chem. 2015, 290, 8677-8692. [CrossRef] [PubMed]

37. Rhee, I.; Davidson, D.; Souza, C.M.; Vacher, J.; Veillette, A. Macrophage fusion is controlled by the cytoplasmic protein tyrosine phosphatase PTP-PEST/PTPN12. Mol. Cell. Biol. 2013, 33, 2458-2469. [CrossRef]

38. Hsieh, H.L.; Wang, H.H.; Wu, C.Y.; Yang, C.M. Reactive Oxygen Species-Dependent c-Fos/Activator Protein 1 Induction Upregulates Heme Oxygenase-1 Expression by Bradykinin in Brain Astrocytes. Antioxid. Redox Signal. 2010, 13, 1829-1844. [CrossRef] 
39. Rochette, L.; Cottin, Y.; Zeller, M.; Vergely, C. Carbon monoxide: Mechanisms of action and potential clinical implications. Pharmacol. Ther. 2013, 137, 133-152. [CrossRef]

40. Kamata, H.; Hirata, H. Redox regulation of cellular signalling. Cell Signal. 1999, 11, 1-14. [CrossRef]

41. Mulier, B.; Rahman, I.; Watchorn, T.; Donaldson, K.; MacNe, W.; Jeffery, P.K. Hydrogen peroxide-induced epithelial injury: The protective role of intracellular nonprotein thiols (NPSH). Eur. Respir. J. 1998, 11, 384-391. [CrossRef] [PubMed]

42. Barbieri, S.S.; Cavalca, V.; Eligini, S.; Brambilla, M.; Caian, A.; Tremoli, E.; Colli, S. Apocynin prevents cyclooxygenase 2 expression in human monocytes through NADPH oxidase and glutathione redox-dependent mechanisms. Free Radic. Biol. Med. 2004, 37, 156-165. [CrossRef] [PubMed]

43. Stanley, A.; Hynes, A.; Brakebusch, C.; Quondamatteo, F. Rho GTPases and Nox dependent ROS production in skin. Is there a connection? Histol. Histopathol. 2012, 27, 1395-1406. [PubMed]

44. Tavares, A.F.; Teixeira, M.; Romao, C.C.; Seixas, J.D.; Nobre, L.S.; Saraiva, L.M. Reactive oxygen species mediate bactericidal killing elicited by carbon monoxide-releasing molecules. J. Biol. Chem. 2011, 286, 26708-26717. [CrossRef] [PubMed]

45. Prabhakar, N.R. NO and CO as second messengers in oxygen sensing in the carotid body. Respir. Physiol. 1999, 115, 161-168. [CrossRef]

46. Choi, Y.K.; Maki, T.; Mandeville, E.T.; Koh, S.H.; Hayakawa, K.; Arai, K.; Kim, Y.M.; Whalen, M.J.; Xing, C.; Wang, X.; et al. Dual effects of carbon monoxide on pericytes and neurogenesis in traumatic brain injury. Nat. Med. 2016, 22, 1335-1341. [CrossRef]

47. Alam, R.; Gorska, M.M. Mitogen-activated protein kinase signalling and ERK1/2 bistability in asthma. Clin. Exp. Allergy 2011, 41, 149-159. [CrossRef]

48. Yuan, X.; Xu, C.; Pan, Z.; Keum, Y.S.; Kim, J.H.; Shen, G.; Yu, S.; Oo, K.T.; Ma, J.; Kong, A.N. Butylated hydroxyanisole regulates ARE-mediated gene expression via Nrf2 coupled with ERK and JNK signaling pathway in HepG2 cells. Mol. Carcinog. 2006, 45, 841-850. [CrossRef]

49. Foresti, R.; Bani-Hani, M.G.; Motterlini, R. Use of carbon monoxide as a therapeutic agent: Promises and challenges. Intensive Care Med. 2008, 34, 649-658. [CrossRef]

50. Pawate, S.; Shen, Q.; Fan, F.; Bhat, N.R. Redox regulation of glial inflammatory response to lipopolysaccharide and interferongamma. J. Neurosci. Res. 2004, 77, 540-551. [CrossRef]

51. Cheng, P.Y.; Lee, Y.M.; Shih, N.L.; Chen, Y.C.; Yen, M.H. Heme oxygenase-1 contributes to the cytoprotection of alpha-lipoic acid via activation of p44/42 mitogen-activated protein kinase in vascular smooth muscle cells. Free Radic. Biol. Med. 2006, 40, 1313-1322. [CrossRef] [PubMed]

52. Sen, C.K.; Packer, L. Antioxidant and redox regulation of gene transcription. FASEB J. 1996, 10, 709-720. [CrossRef] [PubMed]

53. Alam, J.; Igarashi, K.; Immenschuh, S.; Shibahara, S.; Tyrrell, R.M. Regulation of heme oxygenase-1 gene transcription: Recent advances and highlights from the International Conference (Uppsala, 2003) on Heme Oxygenase. Antioxid. Redox Signal. 2004, 6, 924-933. [PubMed]

54. Urquhart, P.; Rosignoli, G.; Cooper, D.; Motterlini, R.; Perretti, M. Carbon monoxide-releasing molecules modulate leukocyte-endothelial interactions under flow. J. Pharmacol. Exp. Ther. 2007, 321, 656-662. [CrossRef] [PubMed]

55. Almolki, A.; Taillé, C.; Martin, G.F.; Jose, P.J.; Zedda, C.; Conti, M.; Megret, J.; Henin, D.; Aubier, M.; Boczkowski, J. Heme oxygenase attenuates allergen-induced airway inflammation and hyperreactivity in guinea pigs. Am. J. Physiol. Lung Cell. Mol. Physiol. 2004, 287, L26-L34. [CrossRef] [PubMed]

56. Sun, B.; Sun, H.; Liu, C.; Shen, J.; Chen, Z.; Chen, X. Role of CO-releasing molecules liberated CO in attenuating leukocytes sequestration and inflammatory responses in the lung of thermally injured mice. J. Surg. Res. 2007, 139, 128-135. [CrossRef]

57. Kilkenny, C.; Browne, W.; Cuthill, I.C.; Emerson, M.; Altman, D.G.; Group NCRRGW. Animal research: Reporting in vivo experiments: The ARRIVE guidelines. Br. J. Pharmacol. 2010, 160, 1577-1579. [CrossRef] [PubMed]

58. McGrath, K.C.; Li, X.H.; McRobb, L.S.; Heather, A.K. Inhibitory Effect of a French Maritime Pine Bark Extract-Based Nutritional Supplement on TNF-alpha-Induced Inflammation and Oxidative Stress in Human Coronary Artery Endothelial Cells. Evid. Based Complement. Altern. Med. 2015, 2015, 260530. [CrossRef] [PubMed] 
59. Hsu, C.K.; Lee, I.T.; Lin, C.C.; Hsiao, L.D.; Yang, C.M. Nox2/ROS-dependent human antigen R translocation contributes to TNF-alpha-induced SOCS-3 expression in human tracheal smooth muscle cells. Am. J. Physiol. Lung Cell. Mol. Physiol. 2014, 306, L521-L533. [CrossRef]

60. Lee, C.W.; Chien, C.S.; Yang, C.M. Lipoteichoic acid-stimulated p42/p44 MAPK activation via Toll-like receptor 2 in tracheal smooth muscle cells. Am. J. Physiol. Lung Cell. Mol. Physiol. 2004, 286, L921-L930. [CrossRef]

61. Hsieh, H.L.; Lin, C.C.; Hsiao, L.D.; Yang, C.M. High glucose induces reactive oxygen species-dependent matrix metalloproteinase-9 expression and cell migration in brain astrocytes. Mol. Neurobiol. 2013, 48, 601-614. [CrossRef] [PubMed]

(C) 2019 by the authors. Licensee MDPI, Basel, Switzerland. This article is an open access article distributed under the terms and conditions of the Creative Commons Attribution (CC BY) license (http://creativecommons.org/licenses/by/4.0/). 